\title{
Where are the returns to lifelong learning?
}

\author{
Michael Coelli* and Domenico Tabasso $^{\dagger}$
}

* Department of Economics, University of Melbourne, Parkville, 3010, Australia; email: mcoelli@unimelb.edu.au

$\dagger$ Department of Economics, University of Essex, Wivenhoe Park, CO4 3SQ, UK and IZA Bonn; email: dtabas@essex.ac.uk

\begin{abstract}
Participation in formal education during adulthood (ages 25 to 54) is a key part of lifelong learning. Employing unique longitudinal data for Australia, we highlight the prevalence of such study, the varied reasons for undertaking it (consumption, career development, job and home disruption), and investigate whether it is socially valuable. Our more detailed estimates of the labour market return to adult education (wage rates, employment, hours of work and occupational status) confirm previous studies that generally found such returns to be small and isolated. We contribute to this literature by also estimating the effect of adult education on job satisfaction and satisfaction with employment opportunities. Increases in satisfaction help rationalise the education enrolment decisions of these adults.
\end{abstract}

JEL Classifications: J24; J28; I23; I28

Keywords: Adult education, lifelong learning, vocational studies, returns to education.

Acknowledgements: We are indebted to Rezida Zakirova for excellent research assistance. We thank Jeff Borland and Moshe Justman for useful comments, along with seminar participants at ESPE 2013 and the University of Melbourne. Central to the analysis are unit record data from the Household, Income and Labour Dynamics in Australia (HILDA) Survey. The HILDA Survey is funded by the Australian Government Department of Social Services (DSS) and managed by the Melbourne Institute of Applied Economic and Social Research (MIAESR). Any interpretation of data is the responsibility of the authors.

Funding: This work was supported by the Australian Government National Centre for Vocational Education Research (NCVER) under the National VET Research and Evaluation Program 20112013 with the MIAESR. The views expressed in this report are those of the authors and do not represent those of the MIAESR or NCVER. 


\section{Introduction}

Technological change and increasing globalisation have led policy-makers and employers to place more emphasis on the importance of the continual skill formation of the workforce, also referred to as 'lifelong learning' (OECD, 2003; Jenkins, 2006). Participation in formal education and training forms a central component of such skill formation. ${ }^{1}$ Globally, participation among adults has grown over time, with $6 \%$ of individuals aged 30 to 39 in OECD member (developed) countries enrolled in formal education and training in 2011 (OECD, 2013), up from 4.5\% in 1996 (OECD, 1998).

Using unique longitudinal survey data, we provide deeper insight into adult education in this paper regarding: (1) its type and prevalence, (2) individual motivation for undertaking it, and most importantly (3) its individual and societal benefits. Understanding societal benefits is central to policy-makers determining public funding of such education. Specifically, we employ data on individuals from the Household, Income and Labour Dynamics in Australia (HILDA) Survey in our analysis. The main benefits of this data source are very detailed information on education enrolment and qualifications held/received, labour market outcomes, and most importantly, individual satisfaction with jobs and employment opportunities. This information is provided annually, allowing us to track individual outcomes from before to after education spells.

The focus of our empirical analysis is estimating the effect of education and training participation on a range of labour market outcomes, using individual fixed effects techniques to minimise potential ability bias. We also allow for differential trends in outcomes among those individuals that do and do not study as adults to further isolate potential causal effects. In addition, we employ a specific instrumental variable strategy following Parent (1999) that overcomes one specific potential source of reverse causality: firm-worker match quality.

We begin by estimating the effect of mature age education on four standard labour market outcomes: probability of employment, wage rate, hours of work and occupational status (prestige). Our main contribution, however, is our ability to estimate the effect of participation on individual satisfaction with their job and satisfaction with their

\footnotetext{
${ }^{1}$ We focus on formal education and training in this article, i.e. study that can lead to the receipt of a formal qualification such as a degree, diploma or certificate. Non-formal training and learning within and outside the workplace are also important components of continual skill formation, but are not analysed here.
} 
employment opportunities. By looking beyond standard outcomes, we can rationalise the study decisions of many prime age adults, a group where returns to education in terms of the standard outcomes are on average small or non-existent.

Prior research of the effect of adult education on the standard labour market outcomes of earnings and employment have generally struggled to find large effects. Returns to adult education were often found to be smaller than returns at more conventional ages, were close to zero for many groups (particularly among older individuals) and positive returns were typically found only for specific subgroups. These prior studies include Blundell et al. (2000), Jenkins et al. (2003), Silles (2007) and Jenkins and Wiggins (2015) for the UK; Albrecht et al. (2005) and Stenberg and Westerlund (2008) for Sweden; and Light (1995) and Jacobson et al. (2005) for the US. Examples for Australia include Karmel and Woods (2004), Headey and Warren (2008), Lee and Coelli (2010), Coelli et al. (2012), ${ }^{2}$ Buchler et al. (2014), Chesters (2014, 2015), and Chesters and Watson $(2014) .^{3}$

Our results for these standard labour market outcomes are generally in line with those presented in this literature. Specifically, we only find positive returns in terms of higher hourly wage rates for males and higher hours of work for females undertaking vocational education and training (VET). ${ }^{4}$

More interestingly, our results reveal positive effects of adult education in terms of higher job satisfaction post-VET study and higher satisfaction with employment opportunities among females. These effects can in turn be linked to the motives for participation among adults. Prime age adults have varied work experiences, many have family responsibilities, and many may have developed a wider variety of interests over time. The motives for participation in education and training as an adult are thus potentially heterogeneous. These motives also often differ from those of younger individuals (more conventional ages for study). Rather than studying purely to obtain employment or a high paying job, many adults study to change careers or for general interest. Given different motives, expected and actual benefits of study may also differ across individuals and by age group, and this is precisely what we find.

\footnotetext{
${ }^{2}$ The analysis reported in this article is an extension and refinement of Coelli et al. (2012).

${ }^{3}$ Note that Buchler et al. (2014) and Chesters (2015) report significant positive effects of mature age education on occupational prestige.

${ }^{4}$ VET qualifications include sub-Bachelor's certificates and diplomas in the Australian system.
} 
Our results have important policy implications. One of the main arguments for public funding of education is that it can result in benefits for society more generally. Increased employment and worker productivity boost economic output and add to public revenues via taxation. If many individuals are undertaking such study for reasons unrelated to "investing" in skill improvement and increasing economic output, benefits for society more generally are potentially lacking. This in turn may call into question public funding of such study.

The outline for the paper is as follows. In the next section, we introduce our data, provide details on adult participation in education, and investigate the heterogeneity in determinants of study. We present our empirical strategies for estimating the effects of adult education in Section 3. Our main estimates of effects are provided in Section 4. In Section 5 we conclude and briefly discuss potential policy implications.

\section{Data and Background}

The HILDA Survey is a nationally representative longitudinal survey of Australian households. In the initial wave of the Survey in 2001, around 7,700 households responded, with information provided for approximately 19,900 individuals aged 15 and older. Respondents are surveyed each year, with detailed information on labour market outcomes, education enrolment and receipt of qualifications collected. For more information about the HILDA Survey, see Watson and Wooden (2010).

In this study, we use data from the 2001 to 2014 waves of the HILDA Survey. To minimise issues related to missing information on enrolment or receipt of qualification, our estimation sample only includes adults aged 25 to 54 in 2001 who responded in all 14 waves. We first select the 8,031 individuals aged 25 to 54 in 2001 who responded in wave 1 . We then restricted our sample to the 4,229 individuals who also responded in all waves from 2002 until 2014. In addition, our estimation sample only includes the subset of individuals 'at risk' in 2001 of starting a new enrolment in formal education. Individuals already studying in 2001 are excluded. This restriction is important, as the labour market outcomes of individuals already studying in 2001 would be affected by such study. It results in the removal of a further 478 observations, leading to a final estimation sample of 3,751 individuals. As explained in section 4, we also exclude a small number of individuals who had more than one education spell between wave 2 and wave 13. Together with the exclusion of some individuals who did not answer all the relevant questions for our analysis, this leads to a final sample of 3,181 individuals. 
Table 1 provides basic patterns of engagement in education broken down by gender and age. These percentages represent enrolment in study towards a formal qualification at any time from 2002 to 2014 , encompassing any enrolment over a 13-year period. ${ }^{5}$ Engagement in education as an adult is quite common, with females more likely to enrol than males. As expected, relatively younger adults are more likely to engage, given that the benefits of further education can accrue over more working years if completed earlier. None-the-less, approximately $21 \%$ of adults aged 45 to 54 in 2001 enrolled in formal education at some stage over the following 13-year period. For both genders and all age groups, certificate level study is the most prevalent, with the only exception of a slight prevalence of Bachelor studies among women in the youngest age group. ${ }^{6}$

[Table 1 Here]

Table 2 provides information on the qualifications held prior to engagement in education as adults. Many adults enrol in study towards a qualification at a lower level than the highest qualification level that they already hold. For example, of all males pursuing a Certificate III or IV as an adult, $13 \%$ already held a Diploma, 14\% already held a Bachelor's degree or higher, and 52\% already held a Certificate III or IV. This last group may be attempting to improve their qualification level from III to IV, but many may simply be attempting to obtain a qualification providing skills closer to those required for their preferred career. Also noteworthy is the high proportion of females studying for certificates that only have 10 or 11 years of high school, or only hold a Certificate I or II. ${ }^{7}$

[Table 2 Here]

Around $38 \%$ of adult students do not complete their qualification (see Table 3). Completion rates are higher among men and lower among those studying for a Bachelor's degree or higher, particularly among females. However, as more students enrol in VET

\footnotetext{
${ }^{5}$ Enrolment rates using all HILDA responders in 2014 are provided in Appendix Table B1.

${ }^{6}$ See Appendix Table A1 for a description of the different educational levels in Australia.

${ }^{7}$ Certificates I and II are generally considered to be a lower level of education attainment than completion of year 12 of high school in Australia.
} 
courses than in University level study, around $70 \%$ of non-completers enrolled in a VET qualification. Overall completion rates tend to fall with age, with some exceptions.

[Table 3 Here]

The relatively low completion rates for University courses among older students, especially women, may be related to the motivations for studying or the difficulties in completing courses which extend over multiple years. Non-completion of VET courses may be an optimal choice for some students. As VET courses are typically administered in modules, many workers may opt out of study after completing those specific modules they deem to be sufficient for their labour market requirements (McVicar and Tabasso, 2016).

To begin to understand the motivation for adult enrolment in education, we construct estimates of the relative importance of various precursors of participation. Potential precursors include demographic characteristics, education qualifications already held and labour market experiences. A focus here is to try to understand whether adults undertake study in response to poor labour market outcomes or for reasons unrelated to the labour market. We estimate models where the outcome is participation in education at any stage from 2002 to 2014 versus no participation, with the covariates all measured in 2001 . We confine our analysis to individuals aged 25 to 54 in 2001 who were not studying in 2001.

We employ inverse probability re-weighting during estimation (Hogan and Lancaster, 2004). This ensures that our estimates using our selected sample (not studying in 2001 and responding in all waves) are representative of the appropriately aged Australian population. We also employ this re-weighting scheme when estimating the effects of mature age education in Section 4. Note that such reweighting is unable to deal with any potential bias in our estimates due to panel attrition or non-response. Attrition and nonresponse, if based on outcomes of interest (e.g. studying, earnings, and job satisfaction), result in regression estimates that are attenuated towards zero (Goldberger, 1981). Our estimates may thus be interpreted as lower bounds on the true effects. However, the HILDA Survey has remarkably low attrition rates (Summerfield et al. 2014), as considerable effort is spent tracking and interviewing all panel members.

Marginal effects for these models estimated using the Probit technique are presented in Appendix Tables A2 and A3 for males and females respectively. The models are estimated for three groups based on employment status: all respondents, employees, and 
all employed individuals. Three separate groups are used because certain 'precursors', such as wage rates or the level of satisfaction with someone's job, could only be collected for specific groups.

For both males and females, education enrolment falls with age and increases with the level of qualification already held: learning begets learning, particularly for males. Female immigrants from non-English speaking countries are less likely to enrol. Enrolment is unrelated to parental background (occupation when aged 15), unlike enrolment at more conventional (younger) ages. Males with disabilities are also less likely to enrol. While unemployed adults are more likely to enrol than the full-time employed, differences are not statistically significant.

Most interestingly for males, enrolment is higher among those with relatively poor job 'quality'. Enrolment is negatively related to a constructed measure of residuals from a standard log wage regression (low wages conditional on education and work experience). ${ }^{8}$ Male enrolment is also negatively related to initial job satisfaction. ${ }^{9}$ Some male enrolment may thus reflect dissatisfaction with current employment and a desire to improve job prospects through additional education.

Most notable for females, enrolment is considerably higher among those suffering from marriage dissolution (separated, widowed and divorced). Some female enrolment may thus be a response to the need to become the main income earner in a family.

While the HILDA Survey is extremely comprehensive, no information is collected on the reasons why individuals choose to study. However, the Australian Bureau of Statistics (ABS) has collected such information in their Surveys of Education and Training (SET). Percentages of individuals by main reason for study are presented in Appendix Table A4, broken down by gender and age group. Among the young (aged below 25), the dominant reason for study is to get a job, as we might expect. But this is much less likely to be the main reason for studying among more mature students.

Among adult students, the main reasons for studying are quite varied. For many, it was a requirement of their job or it was undertaken to obtain skills for their current job. This

\footnotetext{
${ }^{8}$ These log wage regressions included measures of work experience and its square, indicators of highest education level, interactions of work experience and education level, the proportion of time since leaving full-time education not working, immigrant status, marital status, number of children, disability status, and state of residence.

${ }^{9} \mathrm{Job}$ satisfaction is reported on a scale from 0 to 10 . We grouped these reports into four categories.
} 
is in accordance with the view that to just keep up with changes in the world of work often due to technological change - updating work skills is essential. For some, it is to get a different job or promotion, and this is more likely among males than females. Others are studying to change careers or for their personal interest and enjoyment.

To summarize, adult participation in formal education is more common than generally understood, but also very heterogeneous in its nature. It is often unrelated to obtaining higher qualifications, is only completed roughly two-thirds of the time, is more prevalent among males in low 'quality' jobs and post-marriage females, and the main reasons for study are quite varied. It is thus possible that many adults are choosing to study for reasons other than the standard 'economically rational' ones of higher employment probabilities and wage rates.

\section{Estimation Methodology}

The main challenge we face in estimating the effect of education on labour market outcomes is ability/motivation bias. The most able and motivated individuals often obtain higher levels of education and are also likely to be more productive workers, thus more likely to be employed and to earn more. Any observed correlation between education and labour market outcomes may thus not represent a causal effect of education.

We follow recent studies specifically investigating the labour market effects of adult education by exploiting the longitudinal nature of the HILDA Survey data. We compare changes in labour market outcomes from before to after a study spell with changes for similar individuals who did not engage in education over the same period. The labour market effects of any time-constant unobserved differences between those who do and do not engage in education as adults are removed by focusing on within-individual changes. ${ }^{10}$

Specifically, we estimate panel regression models with individual fixed effects, beginning with Equation 1. Each labour market outcome $Y_{i t}$ for individual $i$ in year $t$ is regressed on a subset of individual demographic characteristics that change over time

\footnotetext{
${ }^{10}$ Such strategies have been employed in several recent related studies such as Blanden et al. (2010) for the UK, Zhang and Palameta (2006) for Canada, plus Jepsen et al. (2014) in the US, in addition to several studies listed in the Introduction.
} 
$Z_{i t}{ }^{11}$ indicators of the number of years prior to, during and after an education spell $I_{j i}$; individual fixed effects $\delta_{i}$; and year indicators $\tau_{t}$. The error term $\vartheta_{i t}$ is assumed to be orthogonal to all regressors.

$$
Y_{i t}=Z^{\prime}{ }_{i t} \gamma+\sum_{j=-5}^{6} \alpha_{j} I_{j i}+\delta_{i}+\tau_{t}+\vartheta_{i t}
$$

The indicators $I_{j i}$ are defined as follows. Indicator $I_{-4 i}$ equals one 4 years before individual $i$ begins a new education spell, zero otherwise. Indicators for $j=-3$ and -2 are defined similarly. Variable $I_{-5 i}$ denotes 5 or more years prior to a new education spell. We exclude an indicator denoting the period immediately prior to an education spell for identification. Indicator $I_{0 i}$ represents the year(s) during which an individual is studying. Indicator $I_{1 i}$ equals one in the first year after an education spell has ended, zero otherwise. Indicators for the positive values of $j=2$ to 5 are defined similarly. Variable $I_{6 i}$ denotes 6 or more years after the education spell.

The estimated coefficients $\alpha_{j}$ reveal how each outcome changes from before to after an education spell relative to the outcomes of similar individuals who do not undertake further education. We will thus be able to observe if outcomes dip just before an education spell - a phenomenon often referred to as “Ashenfelter's Dip”, from Ashenfelter (1978) and if outcomes jump up quickly or improve only slowly after an education spell is completed. Note that information on individuals who do not engage in education is used to pin down the estimated coefficients of the time indicators and of the observed timevarying characteristics included in $Z_{i t}$.

While the HILDA Survey contains a considerable level of detail on individuals that is useful in our investigation, sample sizes are not large, and only a subset study as adults. The standard errors on our estimates thus turn out to be larger than we would like. Therefore, we attempt to construct less noisy estimates by imposing restrictions on the values that the $\alpha_{j}$ coefficients can take. Specifically, we estimate the following equation:

$$
Y_{i t}=Z_{i t}^{\prime} \gamma+\alpha_{e t} \cdot \operatorname{tr} \cdot I_{e i}+\alpha_{0} I_{0 i}+\alpha_{a} I_{a i}+\alpha_{a t} \cdot t r \cdot I_{a i}+\delta_{i}+\tau_{t}+\vartheta_{i t}
$$

\footnotetext{
${ }^{11}$ Only coefficients of variables that change over time (marital status, state of residence, disability status and age) are identified once individual fixed effects are included. We include interactions of age and age squared with initial education level indicators to allow lifecycle profiles to differ by education. For estimates of log hourly wages, we also include a quartic in years of work experience.
} 
In this specification, $\operatorname{tr}$ denotes a simple linear time trend, while $I_{e i}$ equals one for all individuals who participate in education during the estimation period, zero otherwise. Indicator $I_{a i}$ denotes periods after an education spell has been completed by individual $i$. This specification has the advantage of identifying whether individuals who participate in education have a lower or higher trend in outcomes prior to the education spell. The estimated effect of education on outcomes - measured by the coefficients $\alpha_{a}$ and $\alpha_{a t}$ is now relative to the continuation of any pre-education trend in outcomes among those who participate relative to those that do not. We will thus be able to identify whether adult education arrests any relative declines in outcomes among those individuals who participate in further education. Note that by allowing for different trends in outcomes among those who study is similar in spirit to the inclusion of individual specific time trends in the related studies of Jacobson et al. (2005) and Huff Stevens et al. (2015).

Including individual fixed effects in our estimated models allows us to deal with one important potential source of endogeneity bias: more able / motivated individuals may choose to study and may have better labour market outcomes even without studying. However, fixed effects alone cannot deal with all potential sources of endogeneity bias. Individuals choosing to study may not only differ from non-students in terms of non-time varying unobservable characteristics. They may also differ in trends in outcomes. Individuals in careers in decline may choose to study to move to careers with improving prospects. Allowing for differential trends in outcomes among those that do and do not study can assist us in dealing with this potential source of estimation bias.

This estimation strategy may still be unable to deal with all potential sources of bias due to reverse causality: current or future shocks to labour market outcomes may induce individuals into further study. One prime example may be changes in firm-worker match quality. Individuals in better firm-worker matches may have higher quality jobs and more support for undertaking further study. Another example may be an unexpected job loss (not evident in a differential trend in pre-job loss outcomes) that induces an individual into further education.

The related empirical literature on employer-provided training includes studies that attempt to deal with endogeneity bias that fixed effects techniques alone may not solve. Several of these studies employ instrumental variable (IV) strategies, using specific variables that are argued to influence the probability of training but are unrelated to labour market shocks or wage growth (Bartel, 1995, Blundell et al., 1996; Kuckulenz and Swick, 2003). The validity of the instruments used in such studies has subsequently been called 
into question (Haelermans and Borghans, 2012; Hidalgo et al., 2014). Other training studies have followed Leuven and Oosterbeek (2008) by employing information on plans to study that are subsequently not fulfilled to potentially create more appropriate control groups for those that do study (the treated). A handful of studies analyse small-scale randomised control trials of training voucher provision (Schwerdt et al, 2012; Hidalgo et al., 2014).

In our setting, however, no information on study plans or outcomes from randomised control trials are available to us. To control for one key potential source of reverse causality (firm-worker match quality), we employ a version of the IV strategy of Parent (1999). In this study of on-the-job training, within job spell variation in training is used as an instrument for training with the current employer, and within individual variation in training with previous employers is used as an instrument for training with previous employers. This strategy can deal with unobserved firm-worker match effects and correlation of prior training with an individual fixed effect. ${ }^{12}$ This approach does not, however, allow us to control for differential trends in labour market outcomes based on studying. Implementing this strategy thus does come at some cost.

To implement the IV strategy, we begin with two indicator variables that separately identify individuals who undertake adult education at the VET and Bachelor's or above levels. Both indicators take the value one during all waves after the education spell has ended, zero otherwise. For individuals who do not undertake any education during the panel, the indicators take the value zero throughout all 14 waves. We then split both these indicators into two: one indicating years after study but still working with the same employer, and the other denoting years after study but in jobs with other employers. The coefficients on these indicators then represent the effect of study on labour market outcomes with the current employer, and the effect of study undertaken while working with previous employers.

The indicators of study with the current employer (VET or Bachelor's and above) are then instrumented by variables constructed as the within-job deviation from the mean of these two current employer study indicators. By construction, these instruments have zero mean at the firm-worker level, so are orthogonal to any permanent firm-worker unobservable characteristic (any match effect). Effectively, this instrumenting strategy

\footnotetext{
${ }^{12}$ Parent's approach heavily draws on the strategy developed by Altonji and Shakotko (1987) to investigate the relation between wages and job seniority.
} 
isolates the evolution of labour market outcomes within a job spell from before to after study. The indicators of study with previous employers are instrumented using variables constructed as the within-individual deviation from the mean of these indicators of study with previous employers. By construction, these instruments are orthogonal to an individual fixed effect. ${ }^{13}$

\section{Estimation Results}

\subsection{Estimates using pre- and post-study indicators}

Figs $1 \mathrm{~A}$ to $1 \mathrm{~F}$ present our main results of the effect of education on labour market outcomes based on estimates of Equation 1. Estimates are provided separately by gender and by two levels of education: certificate or diploma (VET) and Bachelor's degree or above. The dots in these figures represent our estimates of the $\alpha_{j}$ coefficients from Equation 1, while the vertical lines represent $95 \%$ confidence intervals for those estimates. These coefficients are estimated while controlling for individual characteristics that may change over time (age interacted with education level, marital status, geography indicators), plus individual fixed effects and time indicators. These estimated effects cover all individuals who enrolled in education, including those who did not complete the course and receive a formal qualification. ${ }^{14}$

\section{[Figures $1 \mathrm{~A}$ to $1 \mathrm{~F}$ Here]}

Figs 1A to $1 \mathrm{C}$ present our estimates for the standard labour market outcomes investigated in the prior economics literature: probability of employment (1A), hourly wage rates (1B), and weekly work hours (1C). In most instances, the precision of our estimates is not particularly high, thus it is difficult to draw strong conclusions. Overall, the estimates do not reveal significant improvements in these outcomes following study, consistent with prior research within economics.

\footnotetext{
${ }^{13}$ While Parent (1999) employed a generalised least squares estimation technique that allows for correlation of residuals over time within individuals, we implement the IV strategy maintaining the inclusion of individual fixed effects to be consistent with our other estimates.

${ }^{14}$ These estimates were constructed after excluding a small number of individuals that had more than one education spell during the period. Including these multiple education spell individuals did not materially change the estimates, but did lower their precision slightly.
} 
There are, however, a few results worth highlighting. The probability of employment for males undertaking Bachelor's or above study does not improve post-study, although the estimate show an upward trend four or more years' post-study. Note that most Bachelor's or above study undertaken as adults is more likely to be at the post-graduate level. Among males who undertake VET study, there is some evidence of an "Ashenfelter's dip", as employment decreases just prior to study, then gradually improves over time. Among females who enrol in VET, employment is on an upward trend prior to study; the upward trend continues in the first year after study but flattens after the third year post-study. At higher education levels, no clear trend can be detected.

Among males who engage in VET, we detect modest declines in wage rates pre-study, they then jump up during study, and remain at this higher level. We also see a post-study increase in wage rates for males taking Bachelor or above courses, however these effects are not precisely estimated. Among females, there is a short-run upward trend in wage rates post Bachelor's or above study, and no effect for those studying at the VET level. ${ }^{15}$ Males who study at the VET level also tend to report slightly lower weekly hours of work in the post-study period, while hours tend to increase after VET study for females. For both male and female Bachelor or above students we see a (statistically insignificant) decline in working hours only five years after the end of studies. ${ }^{16}$

Looking across Figs $1 \mathrm{~A}$ to $1 \mathrm{C}$, the overall labour market effects of mature age education are modest at best, and positive effects are generally confined to males studying at the VET level. In addition, we do not find a clear effect of study on a fourth measure of labour market performance: the occupational status (prestige) of respondents, measured by the AUSEI06 index developed by McMillan et al. (2009). The results presented in Fig. 1D do not show any clear improvement in the occupational status of respondents after a study spell. The only group for which we can detect a post-study improvement are women who study at a Bachelor or above level, but the improvement is short-term and not precisely estimated. These findings are consistent with our earlier

\footnotetext{
${ }^{15}$ Estimates for hourly wage rates use the subset of individuals who have positive labour market earnings: zero earnings observations were treated as missing during those specific periods only. Estimates in Fig. 1A suggested that employment changes were not large from before to after education. Such a restriction should thus not result in sample selection bias that is particularly troubling.

${ }^{16}$ Note that these estimates only include individuals with positive work hours during the wave (an unbalanced panel).
} 
related work in Coelli et al. (2012), but not with a key finding reported in Buchler et al. (2014). These authors report a significant positive relationship between mature age education and occupational status using the same data. ${ }^{17}$

Now we turn to investigating the effect of mature age education on individual outcomes that many prior Australian studies - concentrating on wage and employment effects - may have missed. We look at the effect of such education on individual job satisfaction (Fig. 1E) and satisfaction with employment opportunities (Fig. 1F).

Regarding job satisfaction, ${ }^{18}$ our estimates differ by gender and level of education. Among males, job satisfaction is marginally lower in the year prior to Bachelor's or above study, but no other trend is evident. Job satisfaction is higher during and after VET study among males relative to years prior to such study. Among females, job satisfaction is generally declining prior to study at both levels then rises during and after study. The lack of a consistent relation between study and job satisfaction is generally in line with the findings of Jenkins and Wiggins (2015), who employ Structural Equation Modelling (SEM) and UK panel data to investigate the relationship between adult education, job satisfaction and overall well-being. They find no direct relationship between adult education and job satisfaction, while there remained a relationship between job satisfaction and overall well-being. ${ }^{19}$

\footnotetext{
${ }^{17}$ There are at least four specification differences between the two studies that are likely to result in the estimates of Buchler et al. (2014) being more positive than those in Coelli et al. (2012) and in this study. Buchler et al. (2014) do not appear to include individual wave (time) indicators, do not differentiate years of study from years prior to study, do not exclude individuals already studying in wave 1 , and do not include interacted education level by age variables as covariates.

${ }^{18}$ Job satisfaction is only measured for employed individuals. It is measured on a scale from zero (totally dissatisfied) to ten (totally satisfied). For simplicity, we model job satisfaction using linear regression.

${ }^{19}$ Using SEM and Spanish cross-sectional data, Fabra and Camison (2009) confirm previous findings in the related literature by reporting a negative direct relationship between education level (not focusing on adult education) and job satisfaction, but a more than offsetting indirect effect via higher wages and better job characteristics.
} 
Our estimates of the effect of enrolment on satisfaction with employment opportunities (Fig. 1F) are reasonably consistent across gender and level of study. Such satisfaction declines pre-study, but increases during and after such study. ${ }^{20}$

\subsection{Estimates using pre- and post-study trends}

We now impose the structure of Equation 2 to potentially improve the precision of our estimates. These estimates allow us to focus on whether study can arrest any declining trends in labour market outcomes among those who study. Rather than report the coefficient estimates directly, we again use diagrams (Figs $2 \mathrm{~A}$ to $2 \mathrm{~F}$ ) to provide a visual display of the key findings. These figures were constructed by: (a) normalising each outcome to equal zero in the year prior to an education spell (for comparability to Figs $1 \mathrm{~A}$ to $1 \mathrm{~F}$ ), and (b) assuming VET study lasts for one year and Bachelor's or above study lasts for two years. These study lengths are the median lengths observed in the data. We also display the results of statistical tests of whether outcomes differ significantly post education from a continuation of the trend observed prior to an education spell.

[Figures $2 \mathrm{~A}$ to $2 \mathrm{~F}$ Here]

In Fig. 2A, estimates of the trend in employment probabilities post Bachelor's or higher study are quite noisy among both males and females, with no significant evidence of improving outcomes post-study. Among females who study at the VET level, the strong upward trend in employment pre-study is not maintained post-study. A naïve comparison of employment probabilities before and after VET study among females reveals higher employment probabilities post-study, but this improvement was already occurring prior to any study taking place.

The benefits from education appear more evident (at least for male workers) when we focus on the second standard measure of labour market outcomes: the hourly wage rate (Fig. 2B). Downward trends in wage rates pre-study appear to reverse post-study among males. The higher precision of estimates for VET study is not surprising, as most adult education is at the VET level. After 6 years, hourly wage rates are nearly $8 \%$ higher than immediately prior to VET study, and approximately $20 \%$ higher than what they would

\footnotetext{
${ }^{20}$ Satisfaction with employment opportunities is measured irrespective of current employment status. It is also measured on a scale from zero (totally dissatisfied) to ten (totally satisfied).
} 
have been if the negative trend had continued. Among females, there is no significant trend in outcomes pre- or post-study at either level.

There are no significant effects of study on weekly work hours evident in Fig. 2C, apart from higher hours in the two years immediately after VET study for females. Similarly, no clear effects of study can be detected with respect to the occupational status of respondents (Fig. 2D). Overall, imposing some structure on the estimates did not reveal much more in terms of positive labour market returns to adult education.

We now turn again to estimating the potential effect of study on job satisfaction and satisfaction with employment opportunities. Once we impose some structure on our estimates, we find consistent positive effects of VET study on job satisfaction for both males and females (Fig. 2E). In all cases, studying appears to arrest a downward trend in job satisfaction. The estimated size of the increase in job satisfaction after VET study is approximately 0.25 points on the zero (totally dissatisfied) to ten (totally satisfied) reporting scale. This is approximately equal to one sixth of a cross-section standard deviation in job satisfaction in our sample of respondents. In comparison, Johnston and Lee (2013) find that job satisfaction increases by only 0.16 points (one tenth of a standard deviation) after a promotion at work.

How might we reconcile the finding of a positive effect of VET study on job satisfaction among females in Fig. 2E but no matching increase in hourly wage rates in Fig. 2B or occupational status in Fig. 2D? Females undertaking VET study were considerably more likely to change occupations and employers around the time of study than either before or after study, and relative to other females who did not study. It was not the case that these occupational changes were necessarily to a higher status occupation. It thus seems that these females used VET study to change to an occupation and employer that was a better overall match for them.

Finally, we find adult education arrests downward trends in satisfaction with employment opportunities among females, but less so among males (Fig. 2F). The estimated size of the increase in satisfaction with employment opportunities among females after study is approximately 0.4 points on the zero to ten scale. This is also approximately equal to one sixth of a cross-section standard deviation in satisfaction with employment opportunities.

Overall, we can conclude that consistent with the 'unrestricted' estimates based on Equation 1, the main 'returns' to mature age education, particularly among females, arise in terms of their satisfaction with their job and employment opportunities, rather than in 
standard measures of labour market success such as employment, hours of work or wage rates.

\subsection{Potential heterogeneity in effects}

The estimates in Figs 1 and 2 represent the average effect among all individuals who undertake study as adults. We are thus pooling individuals that may have quite heterogeneous responses to such education. We repeat the analysis based on Equation 2 for three sample splits representing some of the more likely sources of heterogeneity in estimated effects. These sample splits are:

i. Those who complete their qualification versus those who do not (completers comprise two-thirds of all who study).

ii. Younger adults (25 to 39 in 2001; this group comprises around $45 \%$ of our sample) versus older adults (40 to 54).

iii. Those who study for a qualification at a level that is higher than the highest qualification currently held versus those that study at the same or lower level ('up-skillers' comprise $54 \%$ of all who study).

Rather than present separate sets of figures for all these sub-groups, we provide a summary of our findings for each of our three sample splits in Appendix Tables B2 to B4. We find little evidence that individuals who complete qualifications have any more positive labour market responses to studying than those that studied but did not complete in terms of employment, weekly hours or wage rates. We find some positive effects of education for those who completed their studies only with respect to the hourly wage, which increased for male VET students and female Bachelor or above students. This finding may be due to the preponderance of non-completion among those studying at the VET level. Adults who complete a Bachelor's degree or higher did have larger but often insignificant increases in job satisfaction than those that studied but did not complete. There was little difference in the effects on job satisfaction between completers and noncompleters of VET study. Regarding satisfaction with employment opportunities, female non-completers have more positive responses to studying than do completers, while male Bachelor or above completers were the only male group to have a positive response.

We also found no evidence that younger adults had any more positive labour market responses to studying than older adults in terms of employment and working hours. However, education leads to higher hourly wages for younger male students. This is only 
partly in line with the findings of Blanden et al. (2010) that younger UK adults gained more from studying. Interestingly, regarding job satisfaction and satisfaction with employment opportunities, older men and younger women gained more from Bachelor's or above studies.

Finally, we found that for adults (especially males) who studied at a level higher than the highest qualification already held ('up-skillers') the gains in terms of the standard labour market measures were confined to higher wage rates. Regarding job satisfaction and satisfaction with employment opportunities, the evidence on the subsamples of 'upskillers' and 'not up-skillers' is quite mixed. Female 'up-skillers' at the Bachelor's or above level did gain more than those who studied at similar or lower levels, but the opposite was the case among males.

\subsection{An instrumental variable approach}

Table 4 reports estimates of the effect of mature age education on five of our six labour market outcomes using fixed effects with study instrumented using the Parent (1999) IV technique. Estimates based on standard OLS with individual fixed effects are also provided for comparison. Note that the IV technique we use is reliant on isolation of different firm-worker matches, thus it is not possible to use this technique to estimate the effect of study on the probability of employment (there is no firm-worker match when individuals are not employed). Estimates are again provided separately by gender and after differentiating VET from Bachelor's or above study. Note that all F-tests of instrument strength led to rejection of the null hypothesis of irrelevance, with all statistics exceeding 5,800 .

Standard individual fixed effects estimates using the simple indicators for VET and Bachelor or above study are presented in columns (1) and (4) for males and females respectively. The only statistically significant positive effects we observe here are: higher wages for males post-Bachelor or above study, and higher job satisfaction for males postVET study. Comparing these estimates with those presented in Fig 2, we no longer see positive effects of study in the following cases: wage rates for males post-VET study, job satisfaction for females post-VET study, and satisfaction with employment opportunities for females post-study at either level. The main reason for these differences is that the effects in Fig 2 were identified as breaks from a downward trend observed pre-study, which the simple indicators of columns (1) and (4) of Table 4 are unable to identify. 
The implementation of our version of the Parent (1999) IV estimation strategy requires splitting the study indicators into two, denoting post-study years with the current employer and with later employers. We present the estimates from the IV analysis in columns (3) and (6) for males and females, respectively, and we now focus our discussion on those estimates. For completeness, in columns (2) and (5) of Table 4, we present individual fixed effects estimates after splitting the study indicators.

Focusing on the IV estimates, we now see positive wage rate effects in the male estimates irrespective of level of study and both with current and subsequent employers. The effects are larger for Bachelor's and above study, consistent with our other estimates. Regarding weekly hours of work, we find positive effects for males post-Bachelor's or above study and for females post-VET study, but only with the current employer. We also find a negative hours of work effect for males with later employers. Regarding occupational status, there is a positive effect for females post-Bachelor's or above study with the current employer, but a negative effect for males post-VET study with later employers.

Turning to job satisfaction, there are notable differences between the effects of study with current employers and with later employers. Negative effects are estimated among those remaining with the same employer, while offsetting positive effects are estimated after individuals change employers. Any positive effects of study on job satisfaction only seem to occur if the individual changes employer. As noted above, changes in employer were more prevalent among those who study, and such changes often occurred around the time of study. This is consistent with study at mature ages providing a mechanism for individuals to move to jobs that they find more appealing, even if such jobs do not always lead to higher pay, particularly among females.

Finally, regarding satisfaction with employment opportunities, we only see a positive effect post-VET study among females who change employers. Note that these estimates do not include individuals not working, so these estimates will miss any potential positive effect of study on satisfaction with employment opportunities felt by those not employed.

\section{Concluding remarks}

A growing proportion of working age adults undertake further education at nonconventional ages, with the costs of such education often subsidised at least in part by governments. This article provides new insights into this phenomenon, particularly in 
understanding the magnitude of adult study, why many adults are participating, and what its labour market effects are.

In line with much of the related literature, we found little consistent evidence that adult education leads to significant improvements in the standard labour market outcomes of employment, hours of work or wage rates. There was some consistent evidence of a positive effect of study on the wage rates of males. Yet overall, engaging in formal education as an adult appears to be less economically beneficial than it is for individuals engaging at more conventional (younger) ages, particularly for females. This is a challenging finding, given that a large proportion of adults are engaging in education at some stage (e.g. approximately $21 \%$ of $45-54$ year olds within a 13 -year period).

We did, however, find evidence of education arresting downward trends in job satisfaction and satisfaction with employment opportunities among adults, particularly among females. This effect was found to be related to changes in employer around the time of study. This may rationalise the decision to study as an adult even if standard economic returns are less evident. We also show that the main objective of a large proportion of mature age study is not to gain higher qualification levels, nor is it all motivated by the desire to increase skills and productivity.

Our findings pose important questions for policymakers contemplating the funding of adult study. While studying as an adult can be beneficial for the individual, its benefits for society more generally in terms of higher output, higher tax revenues and potentially lower income support expenditures may be quite limited. Given this, government subsidisation of such study may be difficult to justify (via direct subsidies or tax deductions), particularly for the large number of individuals that have already attained higher level qualifications.

Having said that, there may exist cases where education at more mature ages may be beneficial for individuals and still be desirable for society, particularly in response to job losses in declining industries. Without such re-training, labour market outcomes for such individuals may have deteriorated. In addition, the additional education may have some small benefits outside of the labour market, in terms of increasing overall life satisfaction, health and well-being, crime reduction and civic participation. Such benefits have been highlighted in the sociological literature on mature age education, primarily based on the UK experience (Schuller et al., 2004; Schuller and Watson, 2009; Field, 2009, 2011; Jenkins and Mostafa, 2015). 


\section{References}

Albrecht, J., van den Berg, G.J. and Vroman, S. (2005) The knowledge lift: the Swedish adult education program that aimed to eliminate low worker skill levels, IZA Discussion Papers 1503, Institute for the Study of Labor (IZA).

Altonji, J.G. and Shakotko, R.A. (1987) Do Wages Rise with Job Seniority? Review of Economic Studies, 54, 437-59.

Ashenfelter, O. (1978) Estimating the impact of training programs on earnings, Review of Economics and Statistics, 6, 47-57.

Bartel, A. (1995) Training, wage growth, and job performance: evidence from a company database, Journal of Labor Economics, 13, 401-425.

Blundell, R., Dearden, L. and Meghir, C. (1996) The determinants and effects of workrelated training in Britain, IFS Reports, Institute for Fiscal Studies, No. R50.

Blundell, R., Dearden, L., Goodman, A. and Reed, H. (2000) The returns to higher education in Britain: evidence from a British cohort, The Economic Journal, 110, F8299.

Blanden, J., Buscha, F., Sturgis, P. and Urwin, P. (2010) Measuring the returns to lifelong learning, Centre for the Economics of Education Discussion Paper CEE DP 110, London School of Economics.

Buchler, S., Chesters, J., Higginson, A. and Haynes, M. (2014) Adult learning in Australia: Predictors and outcomes, Chapter 5 in Adult Learning in Modern Societies: An International Comparison from a Life-course Perspective, edited by Blossfeld, H-P, Kilpi-Jakonen, E, Vono de Vilhena, D and Buchholz, S, Edward Elgar Publishing.

Chesters, J. (2014) Learning to adapt: Does returning to education improve labour market outcomes? International Journal of Lifelong Education, 33, 755-69.

Chesters, J. (2015) Within-generation social mobility in Australia: The effect of returning to education on occupational status and earnings, Journal of Sociology, 51, 385-400.

Chesters, J. and Watson, L. (2014) Returns to education for those returning to education: Evidence from Australia, Studies in Higher Education, 39, 1634-48.

Coelli, M., Tabasso, D. and Zakirova, R. (2012) Studying beyond age 25: who does it and what do they gain', A National Vocational Education and Training Research and Evaluation Program Research Report, National Centre for Vocational Education Research (NCVER), Adelaide. 
Fabra, M.E. and Camison, C. (2009) Direct and indirect effects of education on job satisfaction: A structural equation model for the Spanish case, Economics of Education Review, 28, 600-10.

Field, J. (2009) Good for your soul? Adult learning and mental well-being, International Journal of Lifelong Education, 28, 175-91.

Field, J. (2011) Researching the benefits of learning: The persuasive power of longitudinal studies, London Review of Education, 9, 283-92.

Goldberger, A. (1981) Linear regression after selection, Journal of Econometrics, 15, 357 66.

Haelermans, C. and Borghans, L. (2012) Wage effects of on-the-job training: a metaanalysis, British Journal of Industrial Relations, 50, 502-528.

Hidalgo, D., Oosterbeek, H. and Webbink, D. (2014) The impact of training vouchers on low-skilled workers, Labour Economics, 31, 117-128.

Headey, B. and Warren, D. (2008) Adult education and job training, 2001-2005: Who does it? Does it improve future earnings? in Families, Incomes and Jobs, Volume 3: A Statistical Report on Waves 1 to 5 of the HILDA Survey, Melbourne Institute of Applied Economic and Social Research, The University of Melbourne, Melbourne.

Hogan, W.J. and Lancaster, T. (2004) Instrumental variables and inverse probability weighting for causal inference from longitudinal observational studies, Statistical Methods in Medical Research, 13, 17-48.

Huff Stevens, A., Kurlaender, M., and Grosz, M. (2015) Career technical education and labor market outcomes: Evidence from California community colleges, NBER Working Paper No. 21137, April.

Jacobson, L., LaLonde, R., and Sullivan, D.G. (2005) Estimating the returns to community college schooling for displaced workers, Journal of Econometrics, 125, 271304.

Jenkins, A. (2006) Women, lifelong learning and transitions into employment, Work, employment and society, 20, 309-28.

Jenkins, A., Vignoles, A., Wolf, A., and Galindo-Rueda, F. (2003) The determinants and labour market effects of lifelong learning, Applied Economics, 35, 1711-21.

Jenkins, A. and Wiggins, R. (2015) Pathways from adult education to well-being: The Tuijnman model revisited, International Review of Education, 61, 79-97.

Jepsen, C., Troske, K., and Coomes, P. (2014) The labor-market returns to community college degrees, diplomas, and certificates, Journal of Labor Economics, 32, 95-121. 
Johnston, D. and Lee, W.-S. (2013) Extra status and extra stress: Are promotions good for us? ILR Review, 66, 32-54.

Karmel, T. and Woods, D. (2004) Lifelong learning and older workers, Report, National Centre for Vocational Education Research (NCVER), Adelaide.

Kuckulenz, A. and Zwick, T. (2003) The impact of training on earnings - differences between participant groups and training forms. Unpublished manuscript, ZEW Mannheim.

Lee, W.S. and Coelli, M. (2010) Analysis of private returns to vocational education and training, A National Vocational Education and Training Research and Evaluation Program Report, National Centre for Vocational Education Research (NCVER), Adelaide.

Leuven, E. and Oosterbeek, H. (2008) An Alternative Approach to Estimate the Wage Returns to Private-Sector Training, Journal of Applied Econometrics, 23, 423-434.

Light, A. (1995) Hazard model estimates of the decision to reenroll in school, Labour Economics 2, 381-406.

McMillan, J., Beavis, A. and Jones, F.L. (2009) The AUSEI06: a new socioeconomic index of Australia, Journal of Sociology, 45, 123-49.

McVicar, D. and Tabasso, D. (2016) The impact of disadvantage on VET completion and employment gaps, National Centre for Vocational Education Research (NCVER), Adelaide.

OECD - Organisation for Economic Cooperation and Development (1998) Education at a Glance 1998: OECD Indicators, OECD Publishing, Paris.

OECD - Organisation for Economic Cooperation and Development (2003) Beyond Rhetoric: Adult Learning Policies and Practices, OECD Publishing, Paris.

OECD - Organisation for Economic Cooperation and Development (2013) Education at a Glance 2013: OECD Indicators, OECD Publishing, Paris.

Parent, D. (1999) Wages and mobility: the impact of employer-provided training, Journal of Labor Economics, 17, 298-317.

Schuller, T., Preston, J., Hammond, C., Brassett-Grundy, A. and Bynner, J. (2004) The benefits of learning: The impact of education on health, family life and social capital, London: Routledge.

Schuller, T. and Watson, D. (2009) Learning through life: Inquiry into the Future for Lifelong Learning, National Institute of Adult Continuing Education, Leicester. 
Silles, M. (2007) Adult education and earnings: evidence from Britain, Bulletin of Economic Research, 59, 313-26.

Stenberg, A. and Westerlund, O. (2008) Does comprehensive education work for the longterm unemployed? Labour Economics, 15, 54-67.

Summerfield, M., Freidin, S., Hahn, M., Li, N., Macalalad, N., Mundy, L., Watson, N., Wilkins, R. and Wooden, M. (2014) HILDA User Manual-Release 13, Melbourne: Melbourne Institute of Applied Economic and Social Research, University of Melbourne.

Watson, N. and Wooden, M. (2010) The HILDA Survey: progress and future developments, Australian Economic Review, 43, 326-36.

Zhang, X. and Palameta, B. (2006) Participation in adult schooling and its earnings impact in Canada, Analytical Studies Branch Research Paper Series No. 276, Statistics Canada, Ottawa. 
Table 1. Enrolment rates (\%) in formal education, at any time 2002- 2014, HILDA

\begin{tabular}{lccc}
\hline Age group in 2001 & $\mathbf{2 5 - 3 4}$ & $\mathbf{3 5} \mathbf{- 4 4}$ & $\mathbf{4 5} \mathbf{- 5 4}$ \\
\hline Males & & & \\
$\quad$ Any study & 40.00 & 26.42 & 18.92 \\
Of which: & 44.56 & 56.15 & 65.93 \\
$\quad$ Certificate & 14.06 & 9.79 & 3.63 \\
$\quad$ Diploma & 39.70 & 33.71 & 29.35 \\
$\quad$ Bachelor's or above & 1.47 & 0.35 & 1.09 \\
$\quad$ Level not specified & 390 & 564 & 555 \\
Observations & & & 23.55 \\
Females & 46.10 & 32.91 & 61.49 \\
Any study & & & 5.85 \\
Of which: & 46.39 & 55.36 & 29.54 \\
Certificate & 6.01 & 6.16 & 3.12 \\
Diploma & 47.01 & 37.47 & 637 \\
$\quad$ Bachelor's or above & 0.58 & 1.00 & \\
$\quad$ Level not specified & 408 & 626 & \\
Observations & Notes: Percentages constructed using longitudinal weights, individuals not studying in 2001 and \\
responding in all 14 waves from 2001 to 2014. & &
\end{tabular}

Table 2. Initial qualifications of adult students (aged 25 to 54) by level sought, HILDA

\begin{tabular}{|c|c|c|c|c|c|}
\hline & \multicolumn{5}{|c|}{ Level of qualification sought } \\
\hline & $\begin{array}{c}\text { Certificate I } \\
\text { or II } \\
\end{array}$ & $\begin{array}{c}\text { Certificate } \\
\text { III or IV }\end{array}$ & Diploma & Bachelor's & $\begin{array}{c}\text { Postgraduate } \\
\text { degree }\end{array}$ \\
\hline \multicolumn{6}{|c|}{ Highest qualification already held } \\
\hline \multicolumn{6}{|l|}{ Males } \\
\hline Year $10-11$ or Cert I/II & 20.31 & 13.31 & 23.53 & 15.51 & 1.81 \\
\hline Completed year 12 & 7.10 & 8.39 & 8.73 & 11.49 & 3.64 \\
\hline Certificate III / IV & 43.20 & 51.53 & 9.25 & 3.63 & 0.00 \\
\hline Diploma & 5.27 & 12.60 & 38.04 & 20.94 & 2.04 \\
\hline Bachelor's or above & 24.13 & 14.17 & 20.45 & 48.43 & 92.52 \\
\hline TOTAL & 100 & 100 & 100 & 100 & 100 \\
\hline Observations & 151 & 228 & 65 & 79 & 178 \\
\hline \multicolumn{6}{|l|}{ Females } \\
\hline Year $10-11$ or Cert I/II & 49.26 & 20.49 & 20.82 & 3.91 & 0.41 \\
\hline Completed year 12 & 18.45 & 15.86 & 25.45 & 29.49 & 3.25 \\
\hline Certificate III / IV & 6.35 & 41.21 & 12.09 & 9.20 & 0.68 \\
\hline Diploma & 8.02 & 10.15 & 26.22 & 22.57 & 5.04 \\
\hline Bachelor's or above & 17.91 & 12.29 & 15.42 & 34.82 & 90.61 \\
\hline TOTAL & 100 & 100 & 100 & 100 & 100 \\
\hline Observations & 189 & 313 & 61 & 142 & 243 \\
\hline
\end{tabular}

Notes: Percentages constructed using longitudinal weights. Initial education measured in year prior to new education spell. 
Table 3. Completion rates (\%) of formal education, at any time 2002- 2014, HILDA

\begin{tabular}{lcccc}
\hline & \multicolumn{3}{c}{ Age group in $\mathbf{2 0 0 1}$} & \\
& $\mathbf{2 5} \mathbf{- 3 4}$ & $\mathbf{3 5} \mathbf{- 4 4}$ & $\mathbf{4 5} \mathbf{- 5 4}$ & TOTAL \\
\hline Level of qualification sought & & & & \\
Males & & & & \\
VET Certificate or Diploma & 71.61 & 70.96 & 66.73 & 65.83 \\
Bachelor's or above & 61.30 & 51.80 & 56.06 & 62.80 \\
$\quad$ Total & 64.09 & 66.70 & 65.23 & 65.17 \\
$\quad$ Females & & & & \\
VET Certificate or Diploma & 56.74 & 67.39 & 59.58 & 61.36 \\
Bachelor's or above & 55.34 & 54.27 & 38.14 & 52.53 \\
$\quad$ Total & 56.30 & 64.45 & 57.01 & 59.33 \\
\hline Notes: Percentages constructed using longitudinal weights. Enrolment was any time during the \\
$\quad$ years 2002-2012. Completion was any time during the years 2002-2014.
\end{tabular}


Table 4. OLS and IV, with individual fixed effects and time-varying covariates

\begin{tabular}{|c|c|c|c|c|c|c|}
\hline & \multicolumn{3}{|c|}{ MALES } & \multicolumn{3}{|c|}{ FEMALES } \\
\hline & (1) & (2) & (3) & (4) & (5) & (6) \\
\hline & OLS & OLS & IV & OLS & OLS & IV \\
\hline \multicolumn{7}{|l|}{ Log of hourly wage } \\
\hline Bachelor's or above & $\begin{array}{c}0.094 * * \\
(0.045)\end{array}$ & & & $\begin{array}{c}0.024 \\
(0.035)\end{array}$ & & \\
\hline VET & $\begin{array}{c}0.028 \\
(0.023)\end{array}$ & & & $\begin{array}{l}-0.013 \\
(0.018)\end{array}$ & & \\
\hline Bachelor's or above, current & & $\begin{array}{c}0.084 \\
(0.055)\end{array}$ & $\begin{array}{c}0.094 * * \\
(0.041)\end{array}$ & & $\begin{array}{c}0.008 \\
(0.035)\end{array}$ & $\begin{array}{l}-0.004 \\
(0.027)\end{array}$ \\
\hline VET, current & & $\begin{array}{c}0.018 \\
(0.024)\end{array}$ & $\begin{array}{c}0.061 * * \\
(0.020)\end{array}$ & & $\begin{array}{l}-0.007 \\
(0.020)\end{array}$ & $\begin{array}{c}0.000 \\
(0.017)\end{array}$ \\
\hline Bachelor's or above, prior & & $\begin{array}{l}0.117 * \\
(0.064)\end{array}$ & $\begin{array}{c}0.123 * * \\
(0.056)\end{array}$ & & $\begin{array}{c}0.056 \\
(0.056)\end{array}$ & $\begin{array}{c}0.054 \\
(0.039)\end{array}$ \\
\hline VET, prior & & $\begin{array}{c}0.055 \\
(0.043)\end{array}$ & $\begin{array}{c}0.070^{* *} \\
(0.032)\end{array}$ & & $\begin{array}{l}-0.024 \\
(0.029)\end{array}$ & $\begin{array}{l}-0.022 \\
(0.023)\end{array}$ \\
\hline \multicolumn{7}{|l|}{ Weekly hours of work } \\
\hline Bachelor's or above & $\begin{array}{c}1.25 \\
(0.92)\end{array}$ & & & $\begin{array}{c}0.90 \\
(1.15)\end{array}$ & & \\
\hline VET & $\begin{array}{l}-0.14 \\
(0.65)\end{array}$ & & & $\begin{array}{c}0.91 \\
(0.67)\end{array}$ & & \\
\hline Bachelor's or above, current & & $\begin{array}{c}2.49 * * * \\
(0.87)\end{array}$ & $\begin{array}{c}2.20 * * * \\
(0.71)\end{array}$ & & $\begin{array}{c}1.26 \\
(1.03)\end{array}$ & $\begin{array}{c}0.24 \\
(0.79)\end{array}$ \\
\hline VET, current & & $\begin{array}{c}0.49 \\
(0.60)\end{array}$ & $\begin{array}{l}-0.36 \\
(0.44)\end{array}$ & & $\begin{array}{c}1.44 * * \\
(0.71)\end{array}$ & $\begin{array}{l}0.87 * \\
(0.46)\end{array}$ \\
\hline Bachelor's or above, prior & & $\begin{array}{l}-1.42 \\
(1.74)\end{array}$ & $\begin{array}{l}-1.57 \\
(1.21)\end{array}$ & & $\begin{array}{c}0.05 \\
(2.41)\end{array}$ & $\begin{array}{l}-0.24 \\
(1.42)\end{array}$ \\
\hline VET, prior & & $\begin{array}{l}-1.80 \\
(1.39) \\
\end{array}$ & $\begin{array}{c}-2.09 * * \\
(0.89) \\
\end{array}$ & & $\begin{array}{l}-0.10 \\
(1.14) \\
\end{array}$ & $\begin{array}{l}-0.29 \\
(0.69) \\
\end{array}$ \\
\hline Occupational status & & & & & & \\
\hline Bachelor's or above & $\begin{array}{c}1.30 \\
(1.45)\end{array}$ & & & $\begin{array}{c}1.073 \\
(1.139)\end{array}$ & & \\
\hline VET & $\begin{array}{l}-0.20 \\
(0.97)\end{array}$ & & & $\begin{array}{l}-0.276 \\
(0.650)\end{array}$ & & \\
\hline Bachelor's or above, current & & $\begin{array}{c}2.23 \\
(1.46)\end{array}$ & $\begin{array}{c}0.74 \\
(0.99)\end{array}$ & & $\begin{array}{l}1.84 * * \\
(0.91)\end{array}$ & $\begin{array}{l}1.67 * * \\
(0.74)\end{array}$ \\
\hline VET, current & & $\begin{array}{c}0.98 \\
(1.09)\end{array}$ & $\begin{array}{c}0.54 \\
(0.62)\end{array}$ & & $\begin{array}{c}0.16 \\
(0.66)\end{array}$ & $\begin{array}{l}-0.02 \\
(0.50)\end{array}$ \\
\hline Bachelor's or above, prior & & $\begin{array}{l}-0.82 \\
(2.62)\end{array}$ & $\begin{array}{l}-1.36 \\
(1.54)\end{array}$ & & $\begin{array}{l}-0.84 \\
(2.42)\end{array}$ & $\begin{array}{l}-0.89 \\
(1.56)\end{array}$ \\
\hline VET, prior & & $\begin{array}{c}-3.30 * * \\
(1.38)\end{array}$ & $\begin{array}{c}-3.47 * * * \\
(0.89)\end{array}$ & & $\begin{array}{l}-1.13 \\
(1.30)\end{array}$ & $\begin{array}{l}-1.18 \\
(0.79)\end{array}$ \\
\hline
\end{tabular}

Notes: Standard errors in parentheses. ${ }^{*} \mathrm{p}<0.10,{ }^{* *} \mathrm{p}<0.05,{ }^{*} * * \mathrm{p}<0.01$ 
Table 4. (cont.) OLS and IV, with individual fixed effects and time-varying covariates

\begin{tabular}{|c|c|c|c|c|c|c|}
\hline & \multicolumn{3}{|c|}{ MALES } & \multicolumn{3}{|c|}{ FEMALES } \\
\hline & (1) & (2) & (3) & (4) & (5) & (6) \\
\hline & OLS & OLS & IV & OLS & OLS & IV \\
\hline \multicolumn{7}{|l|}{ Job satisfaction } \\
\hline \multirow[t]{2}{*}{ Bachelor's or above } & 0.01 & & & -0.09 & & \\
\hline & $(0.18)$ & & & $(0.13)$ & & \\
\hline \multirow[t]{2}{*}{ VET } & $0.21 * * *$ & & & 0.05 & & \\
\hline & $(0.08)$ & & & $(0.08)$ & & \\
\hline \multirow[t]{2}{*}{ Bachelor's or above, current } & & 0.02 & -0.16 & & $-0.29 * *$ & $-0.33 * * *$ \\
\hline & & $(0.19)$ & $(0.14)$ & & $(0.15)$ & $(0.12)$ \\
\hline \multirow[t]{2}{*}{ VET, current } & & $0.17 * *$ & $-0.13 *$ & & -0.08 & $-0.21 * * *$ \\
\hline & & $(0.08)$ & $(0.07)$ & & $(0.09)$ & $(0.07)$ \\
\hline \multirow[t]{2}{*}{ Bachelor's or above, prior } & & 0.01 & -0.07 & & $0.37 *$ & $0.35^{*}$ \\
\hline & & $(0.29)$ & $(0.19)$ & & $(0.19)$ & $(0.20)$ \\
\hline \multirow[t]{2}{*}{ VET, prior } & & $0.32 * *$ & $0.22 * *$ & & $0.30 * *$ & $0.27 * * *$ \\
\hline & & $(0.13)$ & $(0.11)$ & & $(0.13)$ & $(0.10)$ \\
\hline \multicolumn{7}{|c|}{ Satisfaction with employment opportunities } \\
\hline \multirow[t]{2}{*}{ Bachelor's or above } & -0.11 & & & -0.00 & & \\
\hline & $(0.12)$ & & & $(0.12)$ & & \\
\hline \multirow[t]{2}{*}{ VET } & 0.15 & & & 0.08 & & \\
\hline & $(0.09)$ & & & $(0.10)$ & & \\
\hline \multirow[t]{2}{*}{ Bachelor's or above, current } & & -0.19 & -0.20 & & -0.11 & -0.17 \\
\hline & & $(0.15)$ & $(0.12)$ & & $(0.12)$ & $(0.11)$ \\
\hline \multirow[t]{2}{*}{ VET, current } & & 0.13 & 0.06 & & -0.02 & -0.13 \\
\hline & & $(0.09)$ & $(0.08)$ & & $(0.11)$ & $(0.08)$ \\
\hline \multirow[t]{2}{*}{ Bachelor's or above, prior } & & 0.07 & 0.06 & & 0.24 & 0.22 \\
\hline & & $(0.24)$ & $(0.17)$ & & $(0.22)$ & $(0.18)$ \\
\hline \multirow[t]{2}{*}{ VET, prior } & & 0.18 & 0.16 & & $0.27 *$ & $0.24 * *$ \\
\hline & & $(0.16)$ & $(0.12)$ & & $(0.15)$ & $(0.11)$ \\
\hline
\end{tabular}




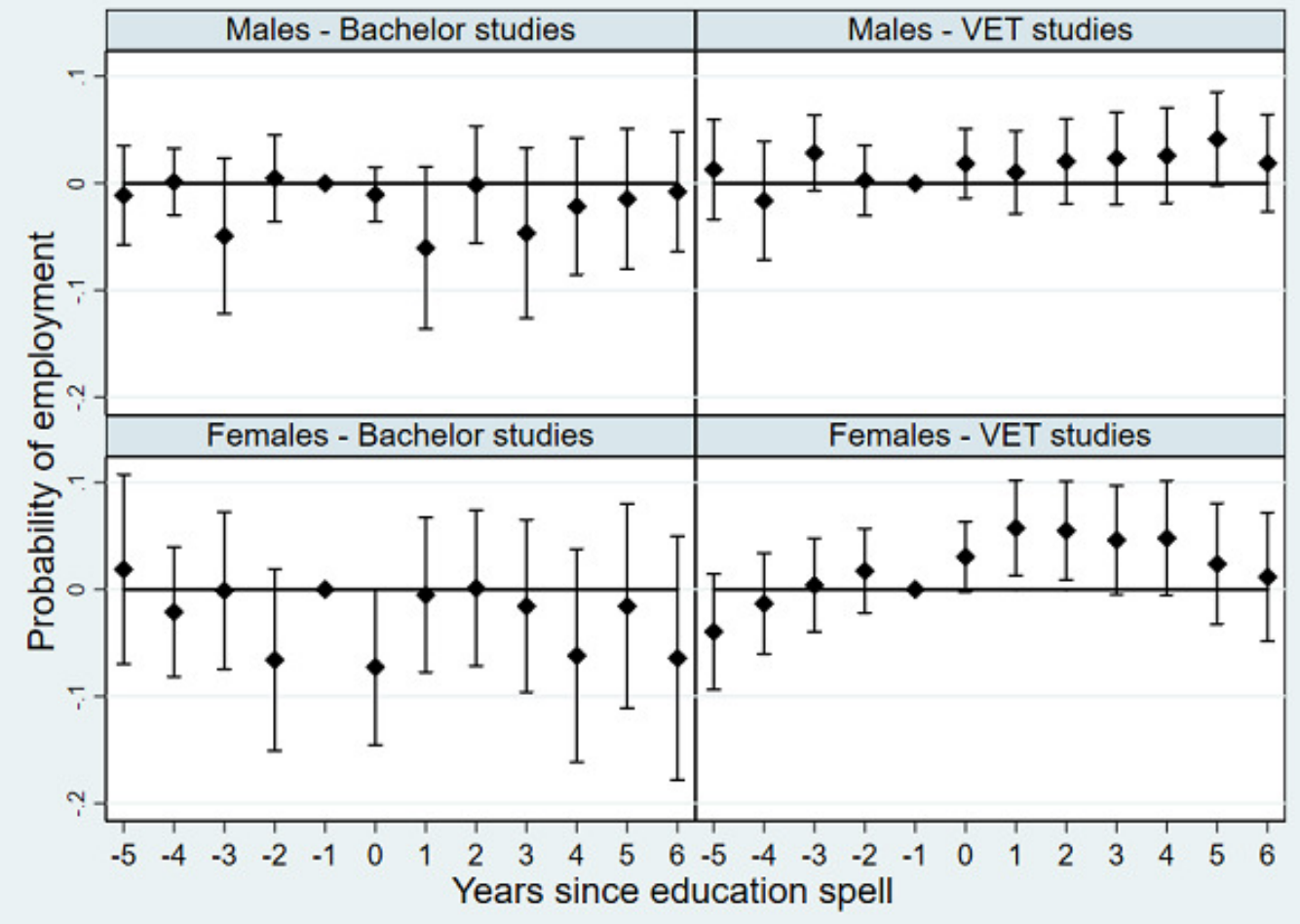

Fig. 1A. Conditional employment probabilities, individual years

Notes: Dots represent estimated coefficients on indicators of years before and after an education spell, estimated using Equation 1. Vertical lines are 95\% confidence intervals on the estimates, constructed using standard errors constructed after allowing clustering at the individual level.

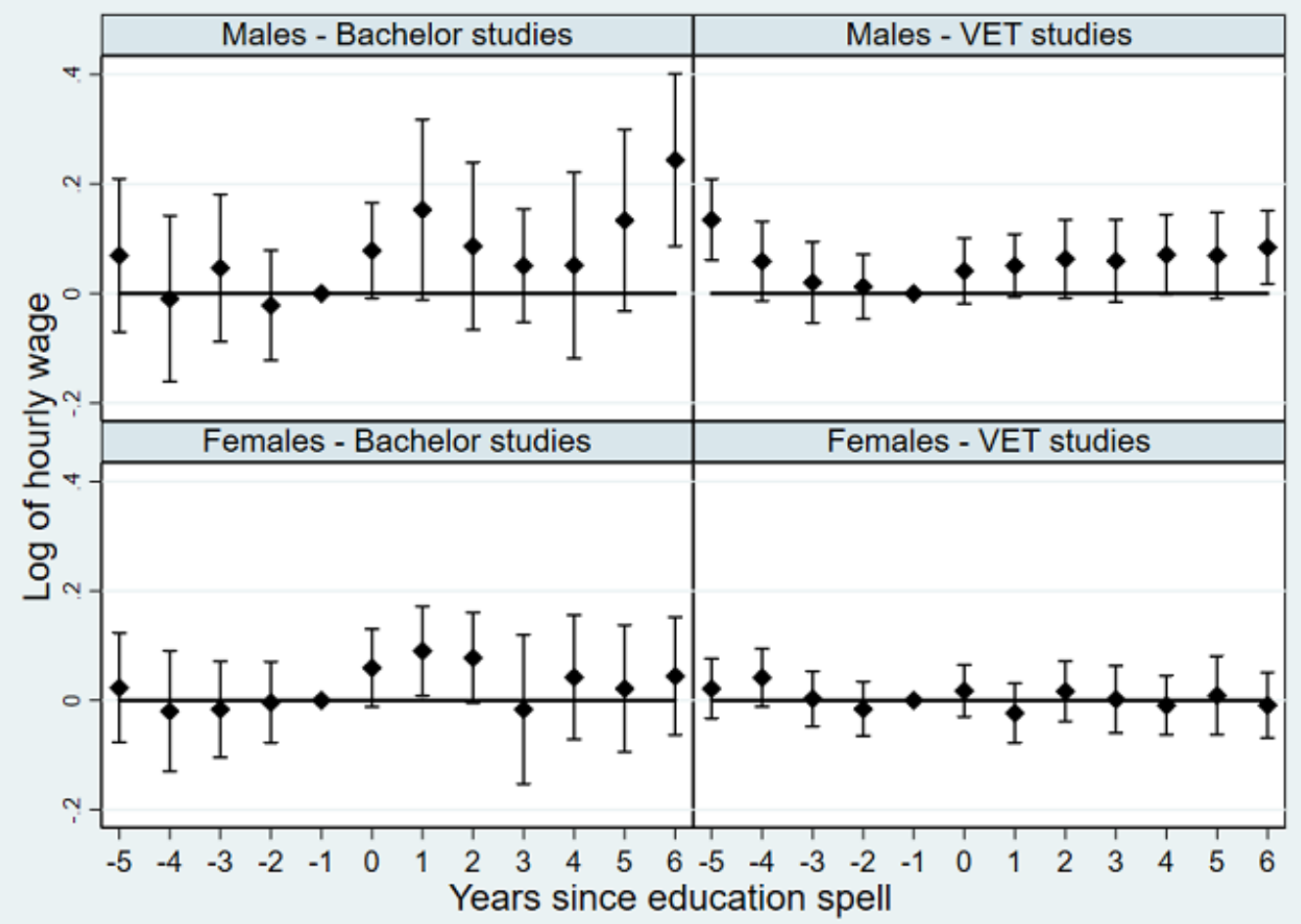

Fig. 1B. Conditional log hourly wage rates, individual years

Notes: See Fig. 1A. 


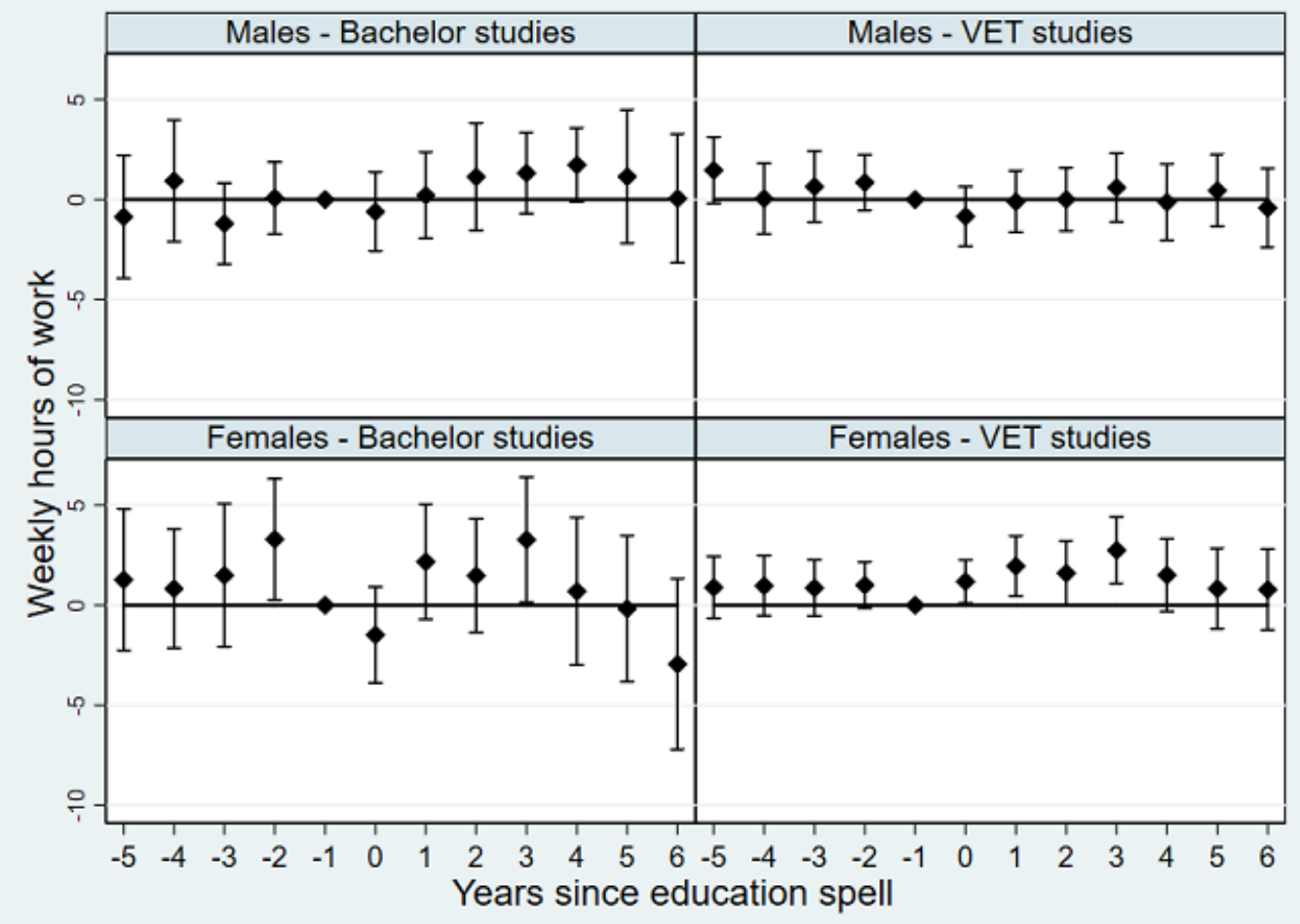

Fig. 1C. Conditional weekly hours of work, individual years Notes: See Fig. 1A.

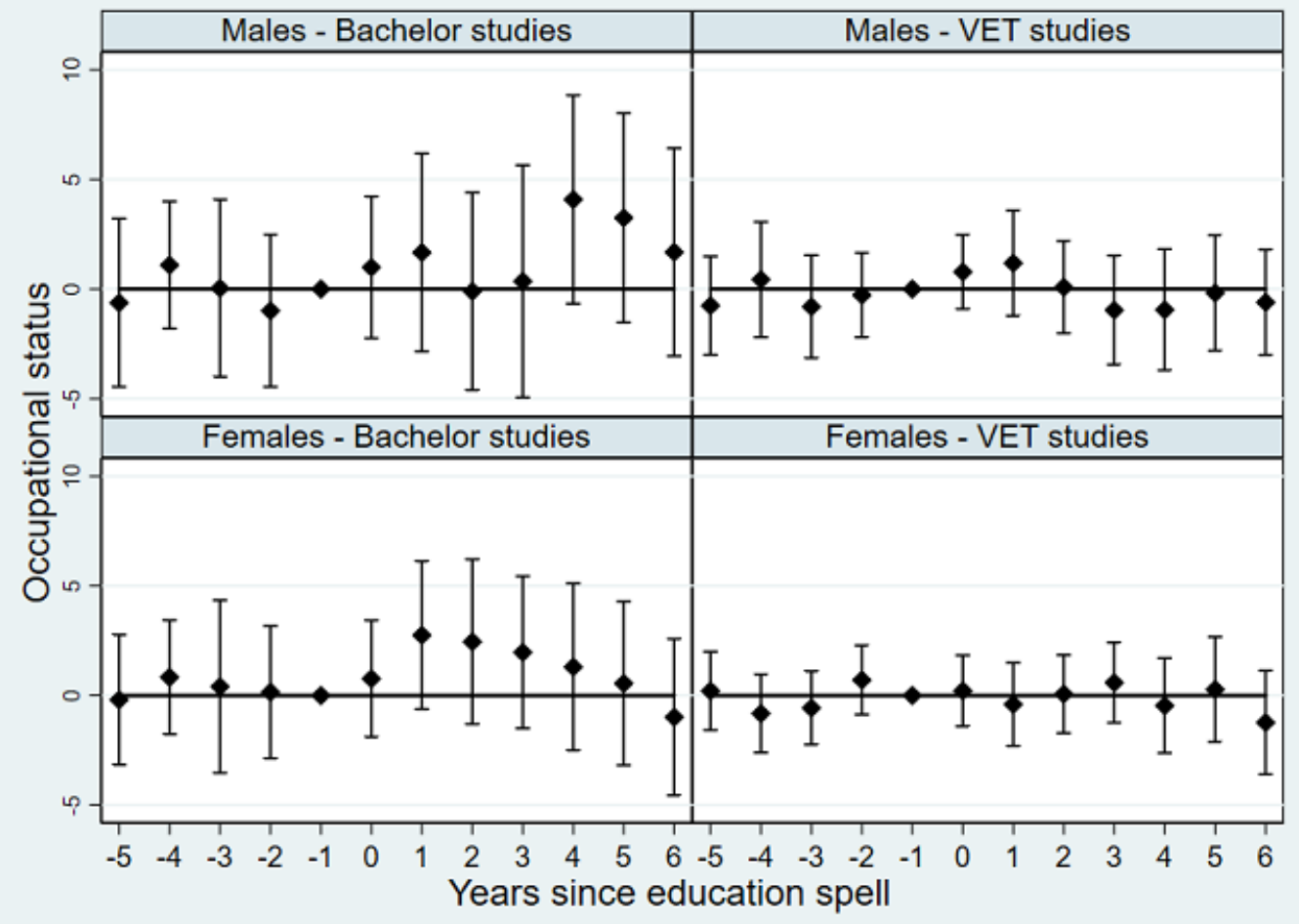

Fig. 1D. Conditional occupational status, individual years

Notes: See Fig. 1A. 


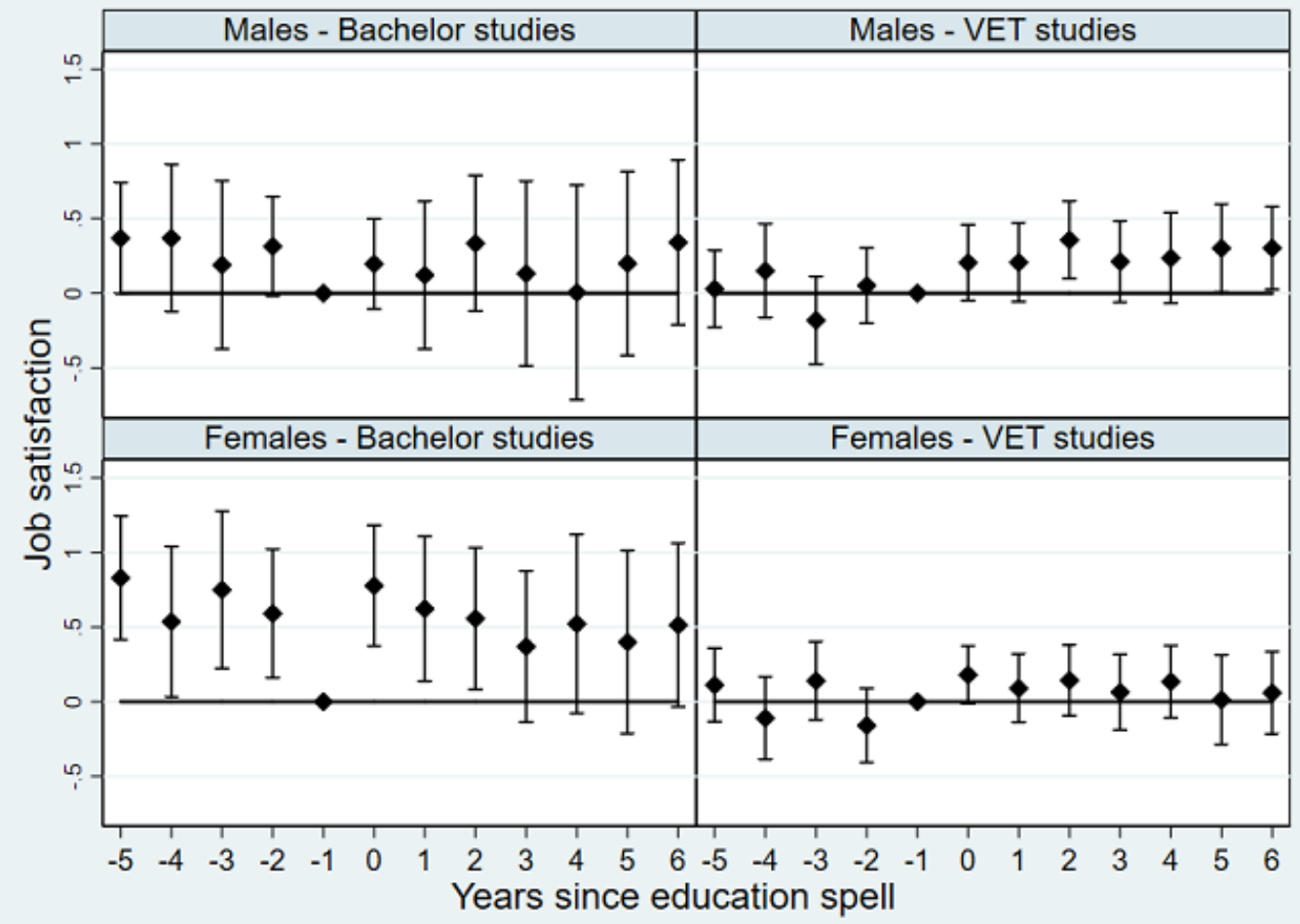

Fig. 1E. Conditional job satisfaction, individual years

Notes: See Fig. 1A.

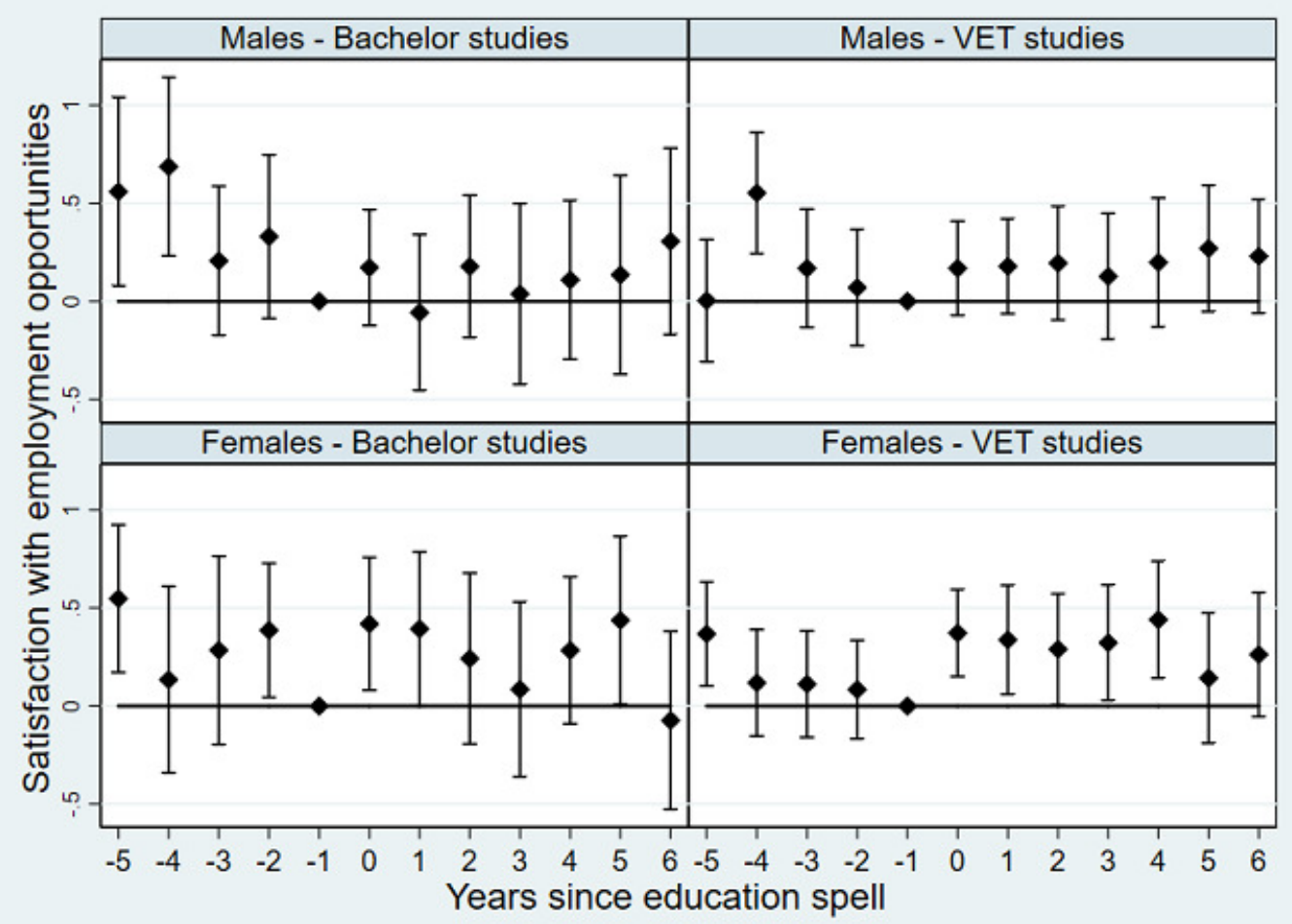

Fig. 1F. Conditional satisfaction with employment opportunities, individual years Notes: See Fig. 1A. 


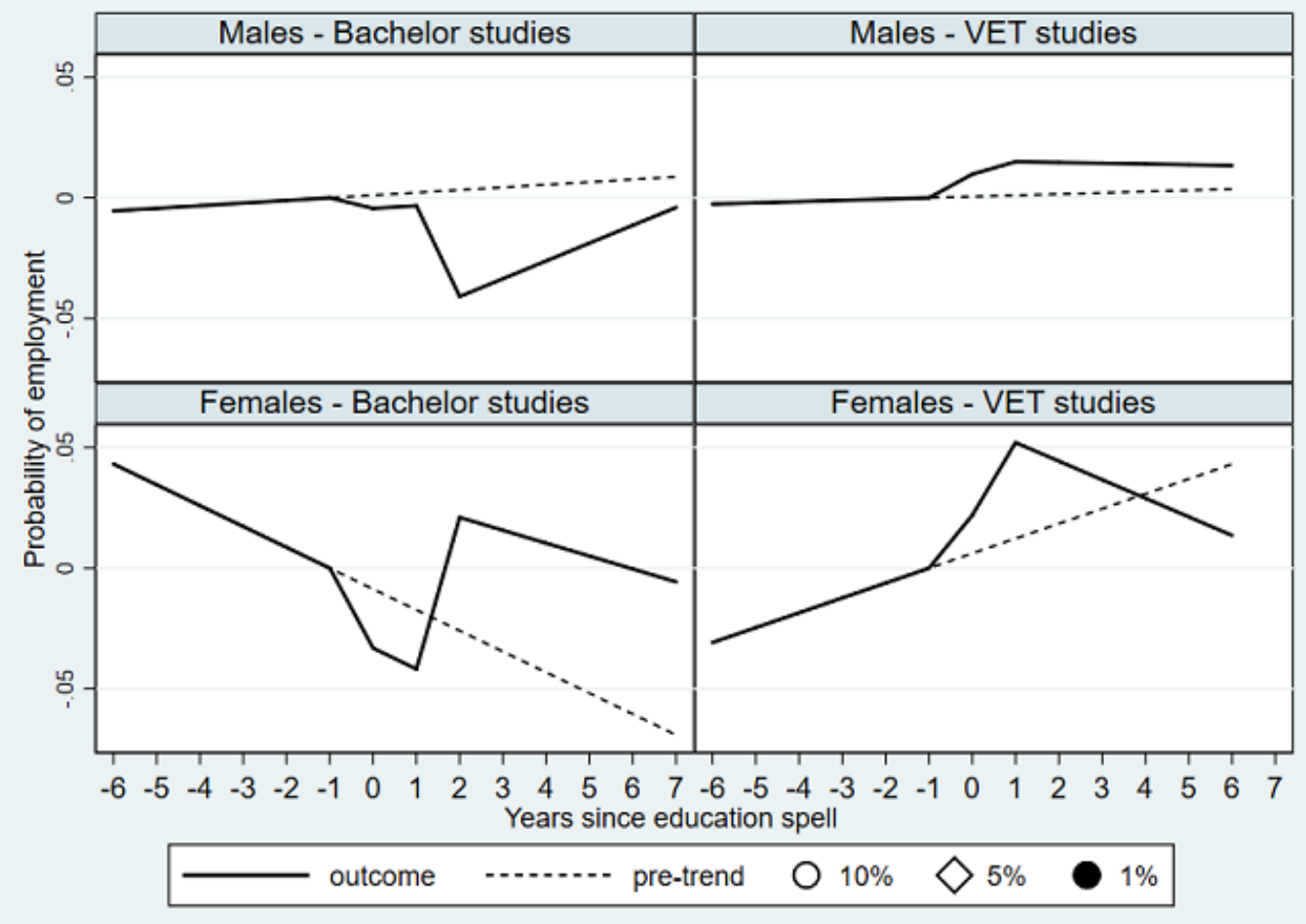

Fig. 2A. Conditional employment probabilities, predicted trends

Notes: Predicted outcomes using estimates of Equation 2. Tests of differences in predicted outcomes from continuation of pre-study trend based on variance-covariance matrix constructed while allowing for clustering at the individual student level.

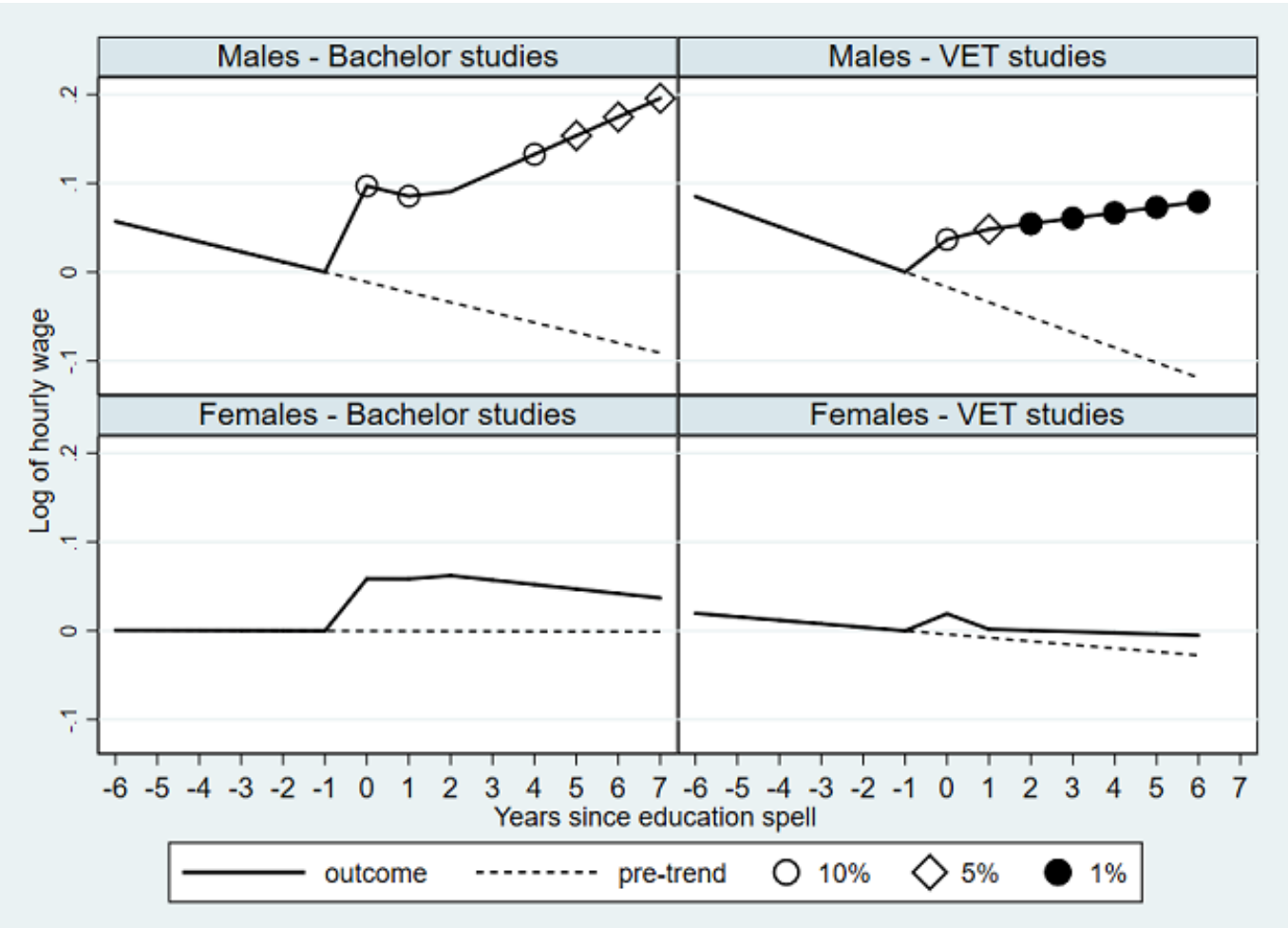

Fig. 2B. Conditional log hourly wage rates, predicted trends

Notes: See Fig. 2A. 


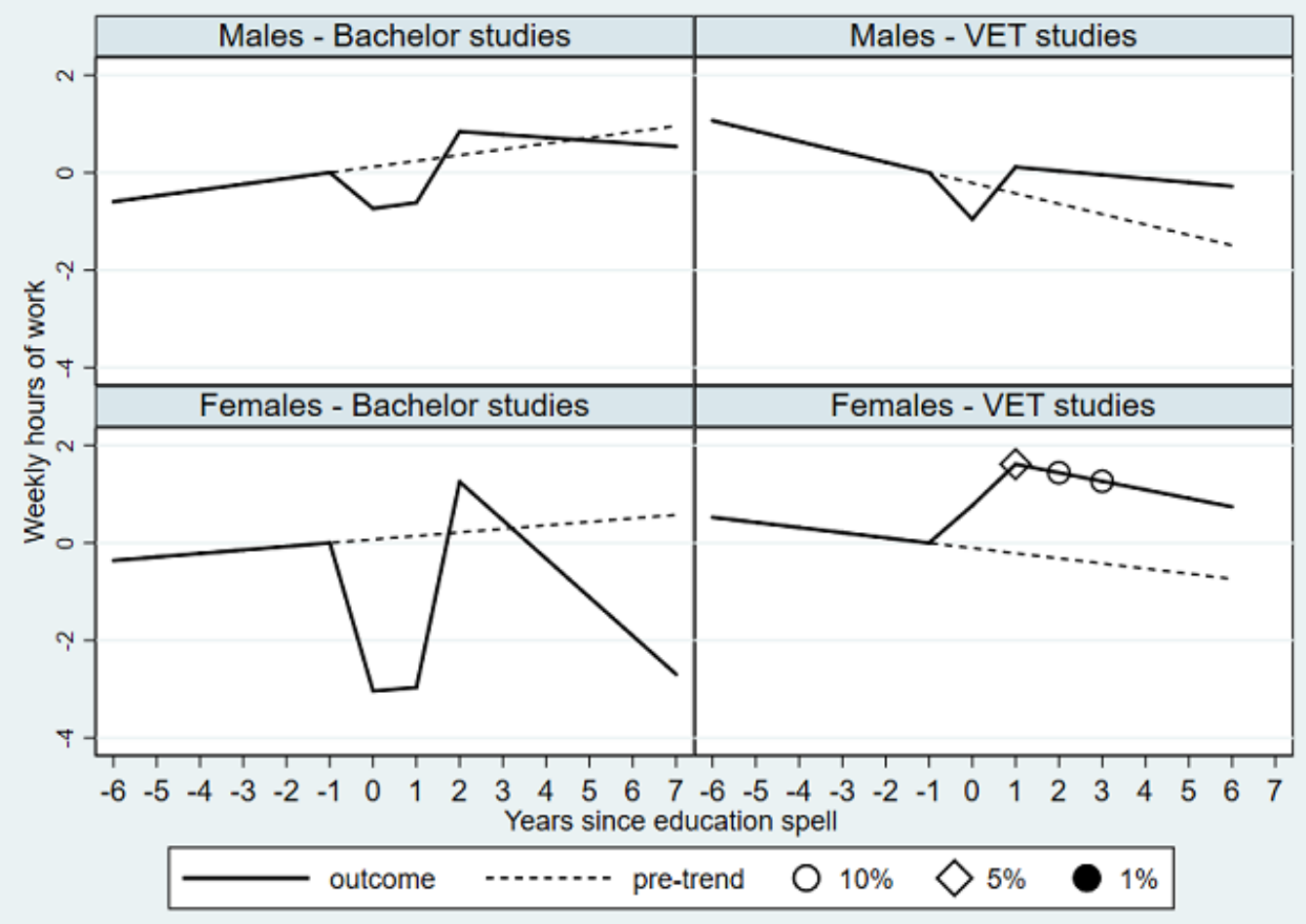

Fig. 2C. Conditional weekly hours of work, predicted trends Notes: See Fig. 2A.

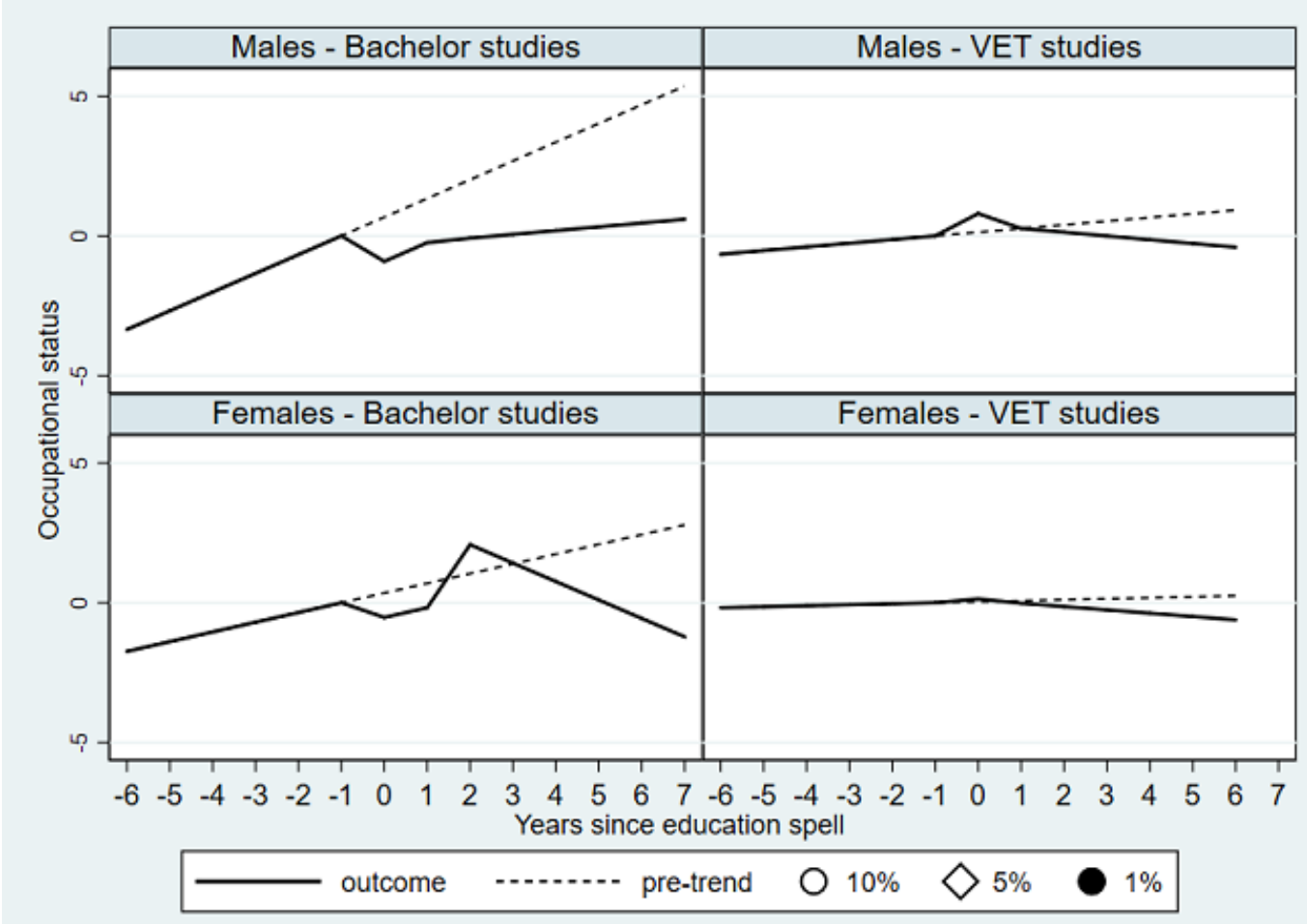

Fig. 2D: Conditional occupational status, predicted trends

Notes: See Fig. 2A. 


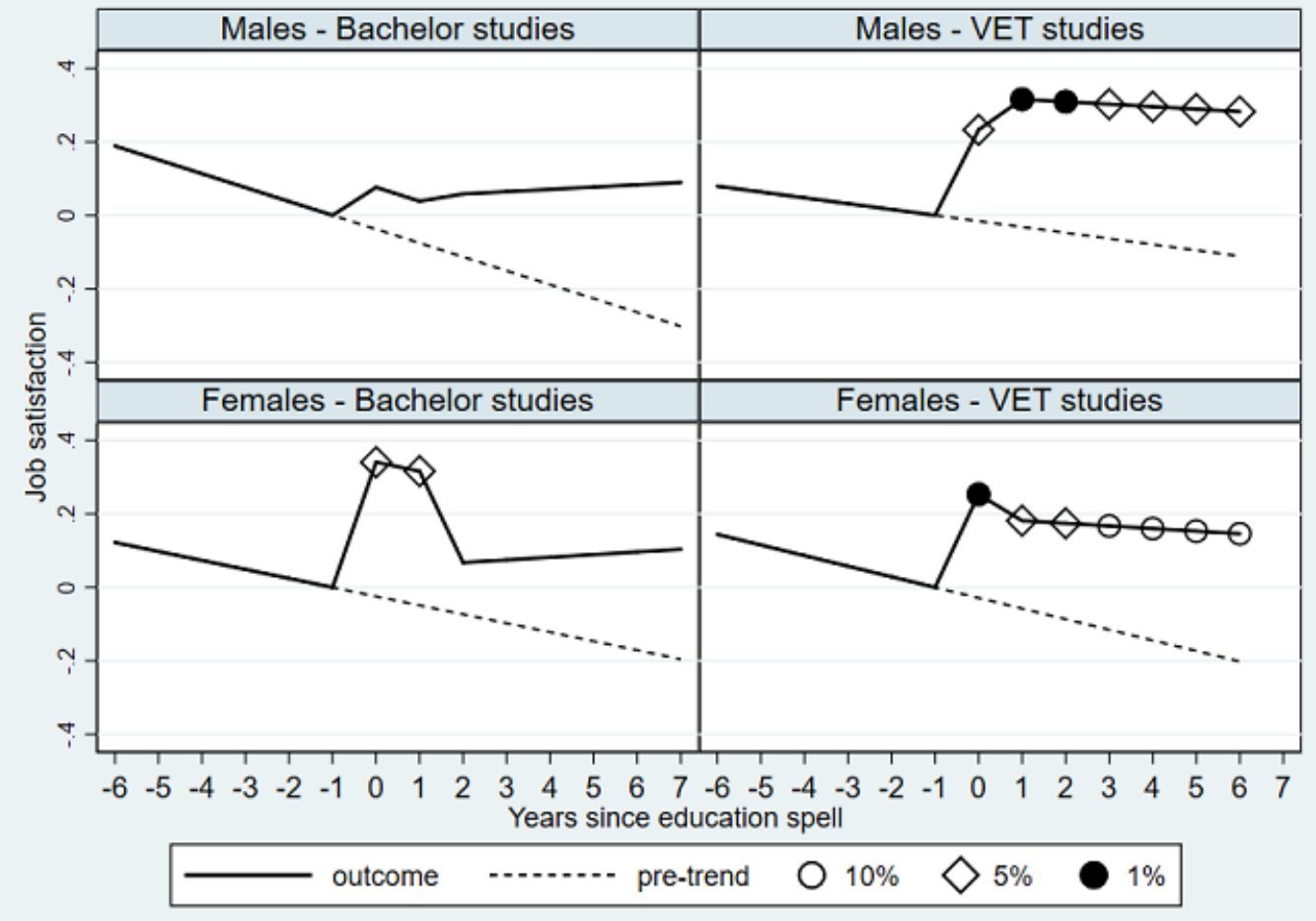

Fig. 2E. Conditional job satisfaction, predicted trends

Notes: See Fig. 2A.

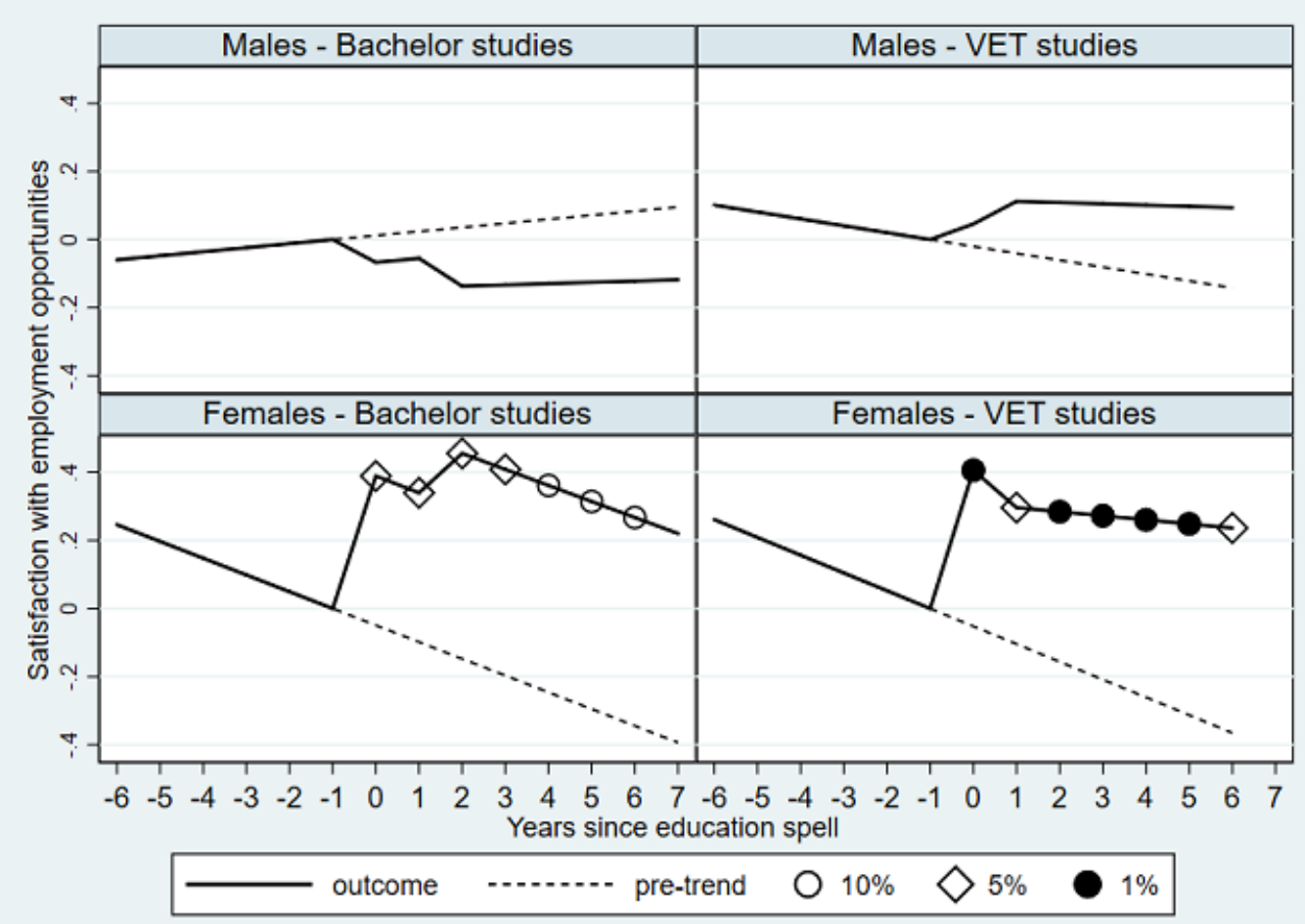

Fig. 2F: Conditional satisfaction with employment opportunities, predicted trends Notes: See Fig. 2A. 


\section{Appendix A}

Table A1. Details of Australian education levels

Education level ISCED code Level description*

Certificate Level I / II

Certificate Level III / IV

$3 \mathrm{C} / 4 \mathrm{~B}$

Diploma and Advanced

Diploma

Bachelor's Degree

Postgraduate Degrees

$2 \mathrm{C}$
These Certificates I qualify individuals with basic functional knowledge and skills to undertake routine work, further learning and community involvement. The volume of learning is typically $0.5-1$ year. Examples: commercial kitchen basic skills, volunteering, pre-apprenticeship plumbing.

These Certificates qualify individuals who apply a broad range of specialised knowledge and skills in varied contexts to undertake skilled work and as a pathway for further learning. The volume of learning $0.5-2$ years. There may be variations between short duration specialist qualifications that build on knowledge and skills already acquired and longer duration qualifications that are designed as entry level requirements for work. Up to 4 years may be required to achieve the learning outcomes through a program of training and employment (apprenticeship). Examples: registered/licensed plumber, teacher's aide.

Diplomas qualify individuals who apply integrated technical and theoretical concepts and/or specialised knowledge in a broad range of contexts to undertake advanced skilled or paraprofessional work and as a pathway for further learning. The volume of learning is typically $1-$ 2 years. Examples: enrolled nurse, draftsman, aircraft maintenance, early childhood educator.

The Bachelor Degree qualifies individuals who apply a broad and coherent body of knowledge in a range of $5 \mathrm{~A}$ contexts to undertake professional work and as a pathway for further learning. The volume of learning is typically $3-$ 4 years. Examples: accountant, engineer, registered nurse.

These Degrees qualify individuals who apply an advanced and substantial body of knowledge in a range of contexts for research and scholarship, as a pathway for further learning and to develop new knowledge. The volume of learning is typically 1-2 years for Master Degrees and 3-4 years for Doctoral Degrees.

\footnotetext{
* Source: see Australian Qualifications Framework January 2013, Australian Qualifications Framework Council, http://www.aqf.edu.au/wp-content/uploads/2013/05/AQF-2nd-Edition-January-2013.pdf
} 
Table A2. Marginal effects on engaging in education, 2002-2014 - males

\begin{tabular}{|c|c|c|c|c|c|c|}
\hline & \multicolumn{2}{|c|}{ All Individuals } & \multicolumn{2}{|c|}{ Employees Only } & \multicolumn{2}{|c|}{ All Employed } \\
\hline & Coeff. & $t$-stat. & Coeff. & $t$-stat. & Coeff. & $t$-stat. \\
\hline \multicolumn{7}{|l|}{ Reference category: age 25-29 } \\
\hline Age $30-34$ & -0.102 & -2.43 & -0.087 & -1.75 & -0.08 & -1.76 \\
\hline Age $35-39$ & -0.166 & -4.24 & -0.197 & -4.39 & -0.159 & -3.75 \\
\hline Age $40-44$ & -0.164 & -4.15 & -0.177 & -3.78 & -0.173 & -4.12 \\
\hline Age $45-49$ & -0.234 & -6.67 & -0.248 & -6.02 & -0.231 & -6.04 \\
\hline Age $50-54$ & -0.275 & -8.49 & -0.286 & -7.50 & -0.258 & -7.15 \\
\hline \multicolumn{7}{|l|}{ Reference category: below Year $11^{*}$} \\
\hline Post-graduate degree & 0.208 & 2.76 & 0.135 & 1.41 & 0.162 & 1.86 \\
\hline Bachelor & 0.254 & 3.71 & 0.136 & 1.54 & 0.188 & 2.35 \\
\hline Advanced diploma / diploma & 0.189 & 2.61 & 0.119 & 1.27 & 0.144 & 1.71 \\
\hline Certificate III / IV & 0.181 & 2.97 & 0.107 & 1.31 & 0.114 & 1.58 \\
\hline Year 12 & 0.074 & 1.22 & 0.037 & 0.46 & 0.013 & 0.19 \\
\hline \multicolumn{7}{|l|}{ Reference category: non-immigrant } \\
\hline Immigrant, English speaking & 0.027 & 0.66 & 0.031 & 0.58 & 0.053 & 1.18 \\
\hline Immigrant, non-English speaking & 0.054 & 1.17 & 0.045 & 0.81 & 0.059 & 1.14 \\
\hline \multicolumn{7}{|c|}{ Reference category: father job status - fourth quartile } \\
\hline Father job status - first quartile & 0.031 & 0.80 & 0.022 & 0.47 & 0.032 & 0.75 \\
\hline Father job status - second quartile & 0.069 & 1.71 & 0.097 & 1.92 & 0.082 & 1.87 \\
\hline Father job status - third quartile & 0.026 & 0.72 & 0.030 & 0.67 & 0.009 & 0.23 \\
\hline \multicolumn{7}{|c|}{ Reference category: mother job status - fourth quartile } \\
\hline Mother job status - first quartile & -0.04 & -1.11 & -0.057 & -1.26 & -0.055 & -1.38 \\
\hline $\begin{array}{l}\text { Mother job status - second } \\
\text { quartile }\end{array}$ & -0.045 & -1.32 & -0.052 & -1.23 & -0.043 & -1.18 \\
\hline Mother job status - third quartile & -0.021 & -0.55 & -0.023 & -0.49 & -0.016 & -0.40 \\
\hline \multicolumn{7}{|c|}{ Reference category: married or de facto } \\
\hline Separated or widowed & 0.138 & 1.73 & 0.204 & 2.14 & 0.182 & 2.12 \\
\hline Divorced & 0.044 & 0.72 & 0.080 & 0.94 & 0.032 & 0.45 \\
\hline Never married & 0.071 & 1.77 & 0.099 & 1.96 & 0.099 & 2.12 \\
\hline Number of dependent children & 0.006 & 0.49 & 0.004 & 0.31 & 0.008 & 0.65 \\
\hline Health limits work & 0.091 & 1.95 & 0.038 & 0.62 & 0.042 & 0.77 \\
\hline Health prevents work & -0.345 & -28.11 & & & & \\
\hline \multicolumn{7}{|c|}{ Reference category: employed full-time } \\
\hline Employed part-time & 0.061 & 1.18 & & & & \\
\hline Unemployed, wants full-time & 0.054 & 0.79 & & & & \\
\hline Unemployed, wants part-time & -0.010 & -0.06 & & & & \\
\hline Not in labour force, marginal & -0.057 & -0.67 & & & & \\
\hline Not in labour force & -0.082 & -1.17 & & & & \\
\hline $\begin{array}{l}\text { Receive disability pension or } \\
\text { support }\end{array}$ & -0.072 & -1.01 & & & & \\
\hline Disposable income (annual \$1000s) & -0.002 & -2.41 & & & -0.002 & -2.80 \\
\hline Log wage residual & & & -0.116 & -3.07 & & \\
\hline Working hours & & & 0.001 & 0.58 & 0.002 & 1.32 \\
\hline Self-employed & & & & & -0.057 & -1.73 \\
\hline \multicolumn{7}{|c|}{ Reference category: skills used in job - do not agree } \\
\hline Skills used in job - strongly agree & & & & & -0.004 & -0.08 \\
\hline Skills used in job - agree & & & & & -0.038 & -0.79 \\
\hline
\end{tabular}


Reference category: job satisfaction - low

Job satisfaction - very high

$-0.125 \quad-2.30$

Job satisfaction - high

$-0.140 \quad-2.56$

Job satisfaction - medium

$-0.157 \quad-3.05$

Observations

1675

1125

1416

Notes: HILDA Data for males aged 25-54 in 2001. Probit regressions include state indicators and indicators of city and regional residence. Coefficients estimated using adjusted weights. Average marginal effects are reported. The t-statistics are based on heteroskedasticityrobust White standard errors.

* Reference category for education levels also includes a small number of individuals with an undefined initial education level.

Table A3. Marginal effects on engaging in education, 2002-2014 - females

\begin{tabular}{|c|c|c|c|c|c|c|}
\hline & \multicolumn{2}{|c|}{ All Individuals } & \multicolumn{2}{|c|}{ Employees Only } & \multicolumn{2}{|c|}{ All Employed } \\
\hline & Coeff. & $t$-stat. & Coeff. & $t$-stat. & Coeff. & t-stat. \\
\hline \multicolumn{7}{|l|}{ Reference category: age 25-29 } \\
\hline Age $30-34$ & -0.021 & -0.48 & 0.008 & 0.14 & -0.027 & -0.47 \\
\hline Age $35-39$ & -0.115 & -2.79 & -0.081 & -1.44 & -0.099 & -1.84 \\
\hline Age $40-44$ & -0.116 & -2.75 & -0.077 & -1.34 & -0.123 & -2.29 \\
\hline Age $45-49$ & -0.215 & -5.64 & -0.168 & -3.17 & -0.192 & -3.90 \\
\hline Age $50-54$ & -0.289 & -8.24 & -0.259 & -5.22 & -0.272 & -5.94 \\
\hline \multicolumn{7}{|l|}{ Reference category: below Year $11^{*}$} \\
\hline Post-graduate degree & 0.088 & 1.48 & 0.066 & 0.83 & 0.078 & 1.00 \\
\hline Bachelor & 0.140 & 2.60 & 0.149 & 2.03 & 0.149 & 2.09 \\
\hline Advanced diploma / diploma & 0.039 & 0.68 & 0.033 & 0.43 & 0.039 & 0.52 \\
\hline Certificate III / IV & 0.122 & 2.24 & 0.113 & 1.45 & 0.058 & 0.77 \\
\hline Year 12 & 0.060 & 1.37 & 0.031 & 0.47 & 0.023 & 0.37 \\
\hline \multicolumn{7}{|l|}{ Reference category: non-immigrant } \\
\hline Immigrant, English speaking & -0.048 & -1.18 & -0.071 & -1.45 & -0.046 & -0.98 \\
\hline Immigrant, non-English speaking & -0.045 & -1.23 & -0.099 & -2.01 & -0.082 & -1.73 \\
\hline \multicolumn{7}{|c|}{ Reference category: father job status - fourth quartile } \\
\hline Father job status - first quartile & 0.027 & 0.77 & 0.057 & 1.21 & 0.100 & 2.24 \\
\hline Father job status - second quartile & 0.037 & 1.09 & 0.027 & 0.61 & 0.068 & 1.63 \\
\hline Father job status - third quartile & 0.025 & 0.75 & 0.045 & 1.05 & 0.090 & 2.22 \\
\hline \multicolumn{7}{|c|}{ Reference category: mother job status - fourth quartile } \\
\hline Mother job status - first quartile & -0.054 & -1.53 & -0.052 & -1.13 & -0.059 & -1.38 \\
\hline $\begin{array}{l}\text { Mother job status - second } \\
\text { quartile }\end{array}$ & -0.047 & -1.42 & -0.045 & -1.04 & -0.050 & -1.25 \\
\hline Mother job status - third quartile & 0.022 & 0.65 & -0.002 & -0.04 & -0.016 & -0.38 \\
\hline \multicolumn{7}{|c|}{ Reference category: married or de facto } \\
\hline Separated or widowed & 0.137 & 2.61 & 0.143 & 2.13 & 0.115 & 1.70 \\
\hline Divorced & 0.188 & 4.13 & 0.147 & 2.63 & 0.176 & 3.19 \\
\hline Never married & 0.079 & 1.83 & 0.075 & 1.43 & 0.075 & 1.46 \\
\hline Number of dependent children & 0.021 & 1.97 & 0.005 & 0.29 & 0.012 & 0.82 \\
\hline Health limits work & 0.074 & 1.95 & 0.077 & 1.36 & 0.079 & 1.50 \\
\hline Health prevents work & 0.111 & 0.31 & & & & \\
\hline
\end{tabular}


Reference category: employed full-time

$-0.047 \quad-1.49$

Unemployed, wants full-time $\quad 0.006 \quad 0.06$

Unemployed, wants part-time $\quad 0.097 \quad 0.75$

Not in labour force, marginal $\quad-0.019 \quad-0.40$

Not in labour force $\quad-0.108 \quad-2.72$

Receive disability pension or

support $\quad-0.202-3.37$

Disposable income (annual \$1000s) $\quad-0.001 \quad-0.89$

$\begin{array}{cccc} & & 0.000 & -0.30 \\ 0.018 & 0.43 & & \\ 0.000 & 0.15 & 0.000 & 0.33 \\ & & -0.069 & -1.61\end{array}$

Self-employed

Reference category: skills used in job - do not agree

$\begin{array}{lll}\text { Skills used in job - strongly agree } & 0.009 & 0.19\end{array}$

$\begin{array}{lll}\text { Skills used in job - agree } & 0.038 & 0.76\end{array}$

Reference category: job satisfaction - low

$\begin{array}{lll}\text { Job satisfaction - very high } & -0.026 & -0.40\end{array}$

$\begin{array}{lll}\text { Job satisfaction - high } & -0.050 & -0.78\end{array}$

Job satisfaction - medium $\quad \begin{array}{ll}-0.016 & -0.23\end{array}$

$\begin{array}{llll}\text { Observations } & 2030 & 1175 & 1328\end{array}$

Notes: HILDA Data for females aged 25-54 in 2001. Probit regressions include state indicators and indicators of city and regional residence. Coefficients estimated using adjusted weights. Average marginal effects are reported. The $t$-statistics are based on heteroskedasticity-robust White standard errors.

* Reference category for education levels also includes a small number of individuals with an undefined initial education level. 
Table A4. Main reason for studying for a formal qualification in previous 12 months

\begin{tabular}{lcccc}
\hline Age group & $15-24$ & $25-39$ & $40-54$ & $55+$ \\
\hline Males & & & & \\
To get into another course of study & 4.4 & 1.0 & 1.1 & -- \\
To get a job & 44.3 & 11.0 & 5.9 & 4.5 \\
To get a different job or promotion & 5.2 & 19.8 & 14.1 & 9.9 \\
Was a requirement of job & 13.2 & 15.3 & 14.6 & 18.0 \\
Wanted extra skills for job & 6.1 & 20.8 & 27.3 & 19.8 \\
To start own business & 3.5 & 2.8 & 2.3 & -- \\
To develop existing business & 0.2 & 1.6 & 4.8 & 1.8 \\
To try for a different career & 3.5 & 9.9 & 7.1 & 8.1 \\
To improve general educational skills & 5.6 & 6.5 & 7.5 & 4.5 \\
To get skills for community/voluntary work & 0.4 & 1.2 & 2.1 & 9.0 \\
To increase confidence/self-esteem & 0.4 & 0.5 & 1.8 & 0.9 \\
For personal interest/enjoyment & 11.2 & 8.3 & 9.8 & 19.8 \\
Other reason & 2.1 & 1.4 & 1.6 & 3.6 \\
& 100 & 100 & 100 & 100 \\
$\quad$ Females & & & & \\
To get into another course of study & 5.0 & 2.7 & 1.1 & 2.2 \\
To get a job & 43.7 & 14.2 & 9.6 & 10.1 \\
To get a different job or promotion & 6.2 & 17.2 & 11.7 & 8.0 \\
Was a requirement of job & 6.1 & 10.9 & 12.6 & 12.3 \\
Wanted extra skills for job & 5.9 & 19.3 & 26.6 & 17.4 \\
To start own business & 2.2 & 2.5 & 3.0 & 3.6 \\
To develop existing business & 0.5 & 1.3 & 2.1 & 0.7 \\
To try for a different career & 4.3 & 11.1 & 9.3 & 5.1 \\
To improve general educational skills & 8.8 & 6.6 & 6.4 & 8.7 \\
To get skills for community/voluntary work & 0.9 & 1.5 & 3.0 & 3.6 \\
To increase confidence/self-esteem & 0.8 & 0.8 & 1.8 & 2.9 \\
For personal interest/enjoyment & 13.2 & 10.6 & 10.4 & 21.0 \\
Other reason & 2.4 & 1.5 & 2.4 & 4.4 \\
& 100 & 100 & 100 & 100 \\
\hline
\end{tabular}

Notes: Constructed from the Survey of Education and Training, 2009 Confidentialised Unit Record File (CURF) provided by the Australian Bureau of Statistics. Excludes students from overseas who are present in Australia purely for study. 


\section{Appendix B (online only)}

Table B1. Current enrolment in formal education and training, 2014 HILDA

\begin{tabular}{|c|c|c|c|c|}
\hline Age group & $25-34$ & $35-44$ & $45-54$ & $55-64$ \\
\hline \multicolumn{5}{|l|}{ Males } \\
\hline Any non-school study & 13.15 & 5.71 & 3.37 & 1.91 \\
\hline \multicolumn{5}{|l|}{ Level } \\
\hline Graduate and post-graduate & 3.45 & 1.50 & 1.15 & 0.58 \\
\hline Bachelor degree & 3.71 & 1.22 & 0.51 & 0.34 \\
\hline Diploma, associate degree & 1.66 & 0.99 & 0.35 & 0.32 \\
\hline Certificate III/IV & 3.42 & 1.44 & 1.06 & 0.58 \\
\hline Certificate $\mathrm{I} / \mathrm{II}$ or other & 0.89 & 0.48 & 0.21 & 0.09 \\
\hline Proportion full-time study & 0.40 & 0.17 & 0.03 & 0.15 \\
\hline Number of observations & 1,240 & 1,118 & 1,220 & 1,071 \\
\hline \multicolumn{5}{|l|}{ Females } \\
\hline Any non-school study & 16.60 & 11.50 & 8.56 & 2.70 \\
\hline \multicolumn{5}{|l|}{ Level } \\
\hline Graduate and post-graduate & 4.39 & 1.88 & 1.49 & 0.49 \\
\hline Bachelor degree & 3.72 & 2.80 & 1.34 & 0.28 \\
\hline Diploma, associate degree & 3.07 & 1.93 & 2.13 & 0.30 \\
\hline Certificate III/IV & 3.88 & 3.59 & 2.97 & 1.16 \\
\hline Certificate I/II or other & 0.83 & 0.93 & 0.63 & 0.44 \\
\hline Proportion full-time study & 0.43 & 0.27 & 0.27 & 0.06 \\
\hline Number of observations & 1,377 & 1,157 & 1,223 & 1,227 \\
\hline
\end{tabular}

Source: HILDA data, weighted statistics. 
Table B2. Completers versus non-completers

Obtaining a new qualification Ended study without qualification

Pre-study trend Education effect Pre-study trend Education effect

\begin{tabular}{|c|c|c|c|c|}
\hline \multicolumn{5}{|l|}{ Male employment } \\
\hline Bachelor or higher & positive & zero & zero & zero \\
\hline VET & zero & zero & positive & zero \\
\hline \multicolumn{5}{|c|}{ Female employment } \\
\hline Bachelor or higher & zero & negative & negative & positive \\
\hline VET & positive & negative & positive & zero \\
\hline \multicolumn{5}{|c|}{ Male log hourly wage } \\
\hline Bachelor or higher & zero & positive & negative & positive*** \\
\hline VET & negative & positive** & negative & positive** \\
\hline \multicolumn{5}{|c|}{ Female log hourly wage } \\
\hline Bachelor or higher & negative & positive* & positive & negative \\
\hline VET & negative & zero & negative & zero \\
\hline \multicolumn{5}{|c|}{ Male weekly hours of work } \\
\hline Bachelor or higher & zero & zero & positive & zero \\
\hline VET & negative & zero & zero & zero \\
\hline \multicolumn{5}{|c|}{ Female weekly hours of work } \\
\hline Bachelor or higher & positive & zero & negative & zero \\
\hline VET & positive & negative & negative & positive \\
\hline \multicolumn{5}{|c|}{ Male occupational status } \\
\hline Bachelor or higher & positive & zero & positive & zero \\
\hline VET & zero & zero & positive & negative \\
\hline \multicolumn{5}{|c|}{ Female occupational status } \\
\hline Bachelor or higher & positive & zero & zero & negative \\
\hline VET & zero & zero & positive & zero \\
\hline \multicolumn{5}{|c|}{ Male job satisfaction } \\
\hline Bachelor or higher & negative & positive & negative & positive \\
\hline VET & positive & zero & positive & positive \\
\hline \multicolumn{5}{|c|}{ Female job satisfaction } \\
\hline Bachelor or higher & negative & positive* & negative & positive \\
\hline VET & zero & positive & negative & zero \\
\hline \multicolumn{5}{|c|}{ Male satisfaction with employment opportunities } \\
\hline Bachelor or higher & negative & positive & negative & zero \\
\hline VET & positive & zero & positive & zero \\
\hline \multicolumn{5}{|c|}{ Female satisfaction with employment opportunities } \\
\hline Bachelor or higher & positive & negative & negative & positive \\
\hline VET & positive & zero & negative & positive* \\
\hline
\end{tabular}

Notes: Summary of effects based on estimates of Equation 2. Statistically significant effects of education at the $10 \%(*), 5 \%(* *)$ and $1 \%(* * *)$ levels, for at least two periods post-study. 
Table B3. Younger versus older adults

Younger (aged 25 to 39 in 2001) $\quad$ Older (aged 40 to 54 in 2001)

Pre-study trend Education effect Pre-study trend Education effect

\begin{tabular}{|c|c|c|c|c|}
\hline \multicolumn{5}{|l|}{ Male employment } \\
\hline Bachelor or higher & positive & negative & negative & zero \\
\hline VET & negative & zero & positive & negative \\
\hline \multicolumn{5}{|c|}{ Female employment } \\
\hline Bachelor or higher & zero & zero & negative & positive** \\
\hline VET & positive & negative & positive & negative \\
\hline \multicolumn{5}{|c|}{ Male log hourly wage } \\
\hline Bachelor or higher & negative & positive** & negative & positive \\
\hline VET & negative & positive*** & negative & positive \\
\hline \multicolumn{5}{|c|}{ Female log hourly wage } \\
\hline Bachelor or higher & zero & positive & zero & positive** \\
\hline VET & zero & zero & negative & positive \\
\hline \multicolumn{5}{|c|}{ Male weekly hours of work } \\
\hline Bachelor or higher & negative & zero & positive & positive \\
\hline VET & negative & zero & negative & zero \\
\hline \multicolumn{5}{|c|}{ Female weekly hours of work } \\
\hline Bachelor or higher & positive & zero & negative & zero \\
\hline VET & zero & zero & positive & negative \\
\hline \multicolumn{5}{|c|}{ Male occupational status } \\
\hline Bachelor or higher & positive & zero & positive & negative \\
\hline VET & positive & negative & negative & zero \\
\hline \multicolumn{5}{|c|}{ Female occupational status } \\
\hline Bachelor or higher & positive & negative & zero & negative \\
\hline VET & zero & zero & positive & negative \\
\hline \multicolumn{5}{|c|}{ Male job satisfaction } \\
\hline Bachelor or higher & negative & positive & negative & positive** \\
\hline VET & zero & positive & positive & zero \\
\hline \multicolumn{5}{|c|}{ Female job satisfaction } \\
\hline Bachelor or higher & negative & positive** & positive & negative \\
\hline VET & negative & zero & zero & positive \\
\hline \multicolumn{5}{|c|}{ Male satisfaction with employment opportunities } \\
\hline Bachelor or higher & negative & positive & negative & zero \\
\hline VET & positive & zero & positive & negative \\
\hline \multicolumn{5}{|c|}{ Female satisfaction with employment opportunities } \\
\hline Bachelor or higher & negative & positive*** & positive & negative \\
\hline VET & negative & zero & negative & positive \\
\hline
\end{tabular}


Table B4. Up-skillers versus no up-skilling

Obtaining higher education level Lower or same education level

Pre-study trend Education effect Pre-study trend Education effect

\begin{tabular}{|c|c|c|c|c|}
\hline \multicolumn{5}{|l|}{ Male employment } \\
\hline Bachelor or higher & positive & negative & zero & positive \\
\hline VET & positive & negative & positive & zero \\
\hline \multicolumn{5}{|c|}{ Female employment } \\
\hline Bachelor or higher & negative & negative & negative & positive \\
\hline VET & positive & negative & positive & negative \\
\hline \multicolumn{5}{|c|}{ Male log hourly wage } \\
\hline Bachelor or higher & negative & positive** & zero & zero \\
\hline VET & negative & positive*** & negative & positive** \\
\hline \multicolumn{5}{|c|}{ Female log hourly wage } \\
\hline Bachelor or higher & negative & positive* & positive & zero \\
\hline VET & positive & zero & negative & zero \\
\hline \multicolumn{5}{|c|}{ Male weekly hours of work } \\
\hline Bachelor or higher & positive & negative & negative & zero \\
\hline VET & negative & negative & negative & positive** \\
\hline \multicolumn{5}{|c|}{ Female weekly hours of work } \\
\hline Bachelor or higher & positive & zero & negative & zero \\
\hline VET & zero & positive & positive & negative \\
\hline \multicolumn{5}{|c|}{ Male occupational status } \\
\hline Bachelor or higher & positive & negative & positive & negative \\
\hline VET & positive & negative & zero & zero \\
\hline \multicolumn{5}{|c|}{ Female occupational status } \\
\hline Bachelor or higher & positive & negative & positive & negative \\
\hline VET & negative & positive & positive & negative \\
\hline \multicolumn{5}{|c|}{ Male job satisfaction } \\
\hline Bachelor or higher & negative & positive & negative & positive* \\
\hline VET & negative & positive & positive & negative \\
\hline \multicolumn{5}{|c|}{ Female job satisfaction } \\
\hline Bachelor or higher & negative & positive ${ }^{* *}$ & positive & zero \\
\hline VET & positive & positive & negative & positive \\
\hline \multicolumn{5}{|c|}{ Male satisfaction with employment opportunities } \\
\hline Bachelor or higher & negative & negative & negative & positive* \\
\hline VET & positive & negative & positive & negative \\
\hline \multicolumn{5}{|c|}{ Female satisfaction with employment opportunities } \\
\hline Bachelor or higher & negative & positive & positive & negative \\
\hline VET & positive & positive & negative & positive \\
\hline
\end{tabular}

